\title{
Effect of process parameters on the microstructure and mechanical properties of AA2024 fabricated using selective laser melting
}

\author{
Mulla Ahmet Pekok ${ }^{1} \cdot$ Rossitza Setchi ${ }^{1} \cdot$ Michael Ryan $^{1} \cdot$ Quanquan $\mathrm{Han}^{2} \cdot$ Dongdong Gu $^{3}$
}

Received: 23 July 2020 / Accepted: 2 November 2020 / Published online: 17 November 2020

(C) The Author(s) 2020

\begin{abstract}
Selective laser melting (SLM) offers significant benefits, including geometric freedom and rapid production, when compared with traditional manufacturing techniques. However, the materials available for SLM production remain limited, restricting the industrial adoption of the technology. The mechanical properties and microstructure of many aluminium alloys have not been fully explored, as their manufacturability using SLM is extremely challenging. This study investigates the effect of laser power, hatch spacing and scanning speed on the mechanical and microstructural properties of as-fabricated aluminium 2024 alloy (AA2024) manufactured using SLM. The results reveal that almost crack-free structures with high relative density (99.9\%) and Archimedes density (99.7\%) have been achieved. It is shown that when using low energy density (ED) levels, large cracks and porosities are a major problem, owing to incomplete fusion; however, small gas pores are prevalent at high-energy densities due to the dissolved gas particles in the melt pool. An inversely proportional relationship between ED and microhardness has also been observed. Lower ED decreases the melt pool size and temperature gradients but increases the cooling rate, creating a finegrained microstructure, which restricts dislocation movement, therefore increasing the microhardness. The highest microhardness $\left(116 \mathrm{HV}_{0.2}\right)$, which was obtained from one of the lowest EDs used $\left(100 \mathrm{~J} / \mathrm{mm}^{3}\right)$, is $45 \%$ higher than as-cast AA2024-0, but $17 \%$ lower than wrought AA2024-T6 alloy.
\end{abstract}

Keywords Selective laser melting - Additive manufacturing - AA2024 P Process parameters - Mechanical properties · Microstructure

\section{Introduction}

Aluminium (Al) and its alloys are extensively used in engineering applications, particularly in the transportation sector. The $2 \mathrm{xxx}$ series of $\mathrm{Al}$ alloys, especially, are preferred by the aerospace industry, owing to their strength, fatigue resistance and damage tolerance, along with high fracture toughness, which allows widespread use in airframe applications [1]. The significance of these alloys (particularly AA2024) in

Rossitza Setchi

setchi@ cardiff.ac.uk

1 Cardiff School of Engineering, Cardiff University, Cardiff CF24 $3 \mathrm{AA}, \mathrm{UK}$

2 School of Mechanical Engineering, Shandong University, Jinan 250061, China

3 College of Materials Science and Technology, Nanjing University of Aeronautics and Astronautics, 29 Yudao Street, Nanjing 210016, China other industrial sectors, including the automotive, construction, marine and defence industries, is also stated, due to their corrosion resistance, conductivity, malleability, recyclability, density and cost [2]. Further improvements in the microstructure and mechanical properties of these alloys using different manufacturing technologies (for instance additive manufacturing) have the potential to introduce this alloy into new research and manufacturing areas $[3,4]$.

In comparison with traditional manufacturing techniques, the layer-by-layer principle of additive manufacturing (AM) provides significant opportunities, such as fast production of geometrically complex items with high precision, reasonable cost, flexible design and short fabrication lead time [5-8]. Selective laser melting (SLM) in particular can process a wide range of metals (i.e. aluminium, iron, nickel, titanium and steel) and their alloys, with the aid of a combination of different technologies, such as computer-aided design (CAD), computer-aided manufacturing (CAM) and computer numerical control (CNC) in one system [9].

High strength $\mathrm{Al}-\mathrm{Cu}-\mathrm{Mg}$ alloys, such as AA2024, however, have some significant drawbacks when processed using 
SLM, where they undergo a similar process to welding. Cracking occurs when high residual thermal stress and temperature gradients emerge in SLM specimens, as a result of rapid melting and high cooling rate of the melt pool [10]. It has been also reported that crack initiation and propagation generally occur when the temperature gradients and residual stresses are high, as the cooling rate of the melt pool can reach $108 \mathrm{~K} / \mathrm{s}$ [10]. Figure 1 shows the relative crack sensitivity of the binary alloy ( $\mathrm{Al}-\mathrm{Cu}, \mathrm{Al}-\mathrm{Mg}$ and $\mathrm{Al}-\mathrm{Si}$ ) compositions. Aluminium (Al) alloys with a copper $(\mathrm{Cu})$ content below 5 $\mathrm{wt} \%$, magnesium $(\mathrm{Mg})$ content under $4 \mathrm{wt} \%$ and silicon $(\mathrm{Si})$ content under $2 \mathrm{wt} \%$ are most susceptible to relative cracking [11]. The aluminium percentage in the binary alloy accounts for the balance of the alloying elements in each composition (Al- $\mathrm{Cu}, \mathrm{Al}-\mathrm{Mg}$ and $\mathrm{Al}-\mathrm{Si})$. The weight ratios of $\mathrm{Cu}(4.9$ $\mathrm{wt} \%), \mathrm{Mg}(1.8 \mathrm{wt} \%)$ and $\mathrm{Si}(0.5 \mathrm{wt} \%)$, therefore, make AA2024 particularly challenging to process. Moreover, possible evaporation of the alloying elements (such as Mg, owing to the low boiling point) may cause the loss of the elements and bring the weight ratios closer to the peak points of the relative crack sensitivity curves [12], further increasing the relative crack sensitivity more for the AA2024 alloy.

The high reflectivity of these alloys also prevents absorption of the laser power, and therefore, complete melting of the powder is restricted; it has been reported that $\mathrm{Al}$ can only absorb $7 \%$ of the laser energy at $1 \mu \mathrm{m}$ wavelength [14]. Si, however, can absorb $70 \%$ of the laser energy, which assists in melting the Al powder by transferring the absorbed energy into the $\mathrm{Al}$ [15]. However, the Si percentage in AA2024 is only $0.5 \mathrm{wt} \%$, which again limits the laser energy absorption. Consequently, processing with lower energy density (ED) can lead to an increase in the melt pool viscosity, irregular surfaces, and unmelted powder particles; however, higher ED may create material stacking, which causes material bumps on the surface owing to the movement of the molten material from the centre to the back section of the melt pool [16]. Moreover, excessive ED may lead to the formation of surface balls, discontinuous scan tracks and unsmooth surfaces, due to the high evaporation of the elements [16]. Meanwhile, poor followability and high thermal conductivity of the powder are other substantial shortcomings of AA2024 for SLM. These drawbacks have not been fully explored to date.

Several studies have investigated the mechanical properties and microstructure of high-strength $\mathrm{Al}-\mathrm{Cu}$ alloys. The processing, microstructure and mechanical properties of wrought $\mathrm{Al}-\mathrm{Cu}-\mathrm{Mg}$ alloy produced using SLM have been studied, and it has been reported that fewer cracks and higher-density specimens of high strength $\mathrm{Al}-\mathrm{Cu}-\mathrm{Mg}$ alloy can be obtained above an energy level threshold of $340 \mathrm{~J} / \mathrm{mm}^{3}$ [17]. The effect of processing parameters on the relative densities of 2022 and 2024 grade Al alloys processed by powder-bed laser beam melting (LBM, also known as SLM) has also been studied, and relative densities of $99.5 \%$ and $99.9 \%$, respectively, achieved from small cubic specimens built on supports [18]. It is shown that, in comparison with cubes built directly on the platform, cubes built on support structures have higher relative density because air among the powder particles and a reduced contact area with the building plate prevents heat from being conducted away as easily, and it is therefore isolated in the melt pool [18]. It is also reported that larger components with more complex shapes may contain additional problems, such as higher residual stresses in the melt pool, and more hot and cold cracks [18]. However, neither laser power higher than $100 \mathrm{~W}$ nor the mechanical properties of the alloys were examined, with the study limited to examining the relative density and chemical analysis of the as-fabricated specimens [18]. The inner relative density of 2219 and 2618 grade $\mathrm{Al}$ alloys, fabricated using LBM, has also been studied; relative densities of $99.94 \%$ and $99.97 \%$ respectively were achieved, and it is reported that slower consolidation allows the melted powder to fill the cracks while still liquid [19]. Although some parameters, including scanning speed, hatch spacing distance and exposure time, were examined in these studies, the laser power for the cubic specimens was kept constant at $100 \mathrm{~W}$ [19]. In order to fully understand the effect of the process parameters on the alloy, further experimental work into the microstructure and mechanical properties of the alloy is therefore required.

Accordingly, this study investigates the effect of various EDs on as-fabricated AA2024 alloy specimens produced using SLM. The focus of the study is the mechanical and microstructural changes in the as-fabricated samples produced
Fig. 1 The effect of alloying elements on the relative crack sensitivity of AA2024 [11-13]

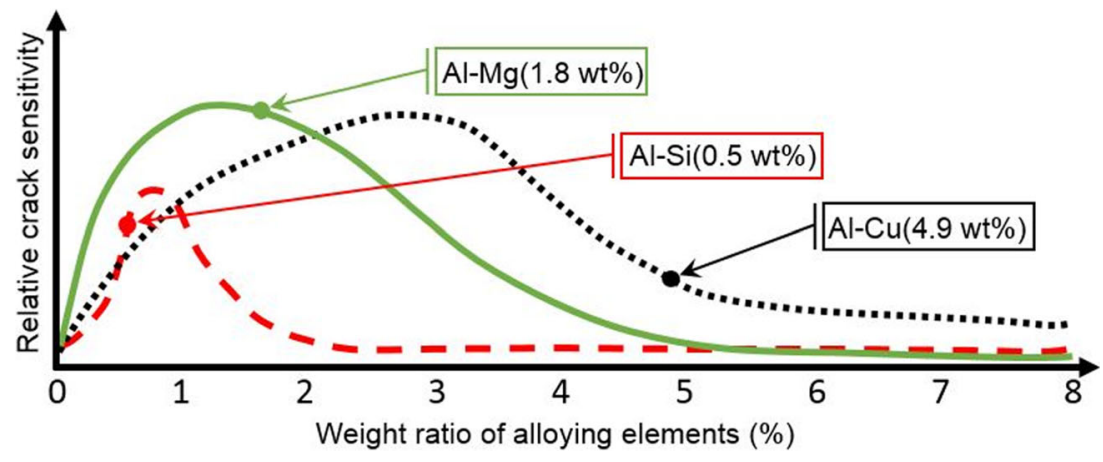


under different processing parameters, such as laser power, scanning speed and hatch spacing. Thus, the contribution of this study is to increase in-depth understanding of the relationship between ED, processing parameters and the achieved results in the as-fabricated specimens. Laser power is varied from 100 to $200 \mathrm{~W}$, hatch spacing from 40 to $100 \mu \mathrm{m}$ and scanning speed from 98 to $727 \mathrm{~mm} / \mathrm{s}$. The effects of these parameters, on the microhardness, porosity, tensile strength, Archimedes density and relative density, are systematically analysed. Additionally, this study offers some practical advice for successfully manufacturing the alloy using SLM.

\section{Experimental details}

\subsection{Powder specification}

Gas atomised AA2024 powder was obtained from LPW Technology Limited. The chemical composition of the powder is $4.9 \mathrm{Cu}-1.8 \mathrm{Mg}-0.9 \mathrm{Mn}-0.5 \mathrm{Si}-0.5 \mathrm{Fe}-\mathrm{bal} . \mathrm{Al}$ (wt $\%$ ), and the particle size range is between 2 and $86 \mu \mathrm{m}$, with an average particle size of $37 \mu \mathrm{m}$ (see Fig. 3), obtained using a Malvern Mastersizer-3000 (Malvern, UK).

\subsection{Manufacturing process}

This study contains two experiments which examine the effect of different processing parameters. In experiment 1 , the laser power (from 100 to $200 \mathrm{~W}$ ) and scanning speed (from 98 to $727 \mathrm{~mm} / \mathrm{s}$ ) parameters were varied in order to understand the effect of these parameters on the properties of as-fabricated samples (see Table 1). Laser powers below $100 \mathrm{~W}$ are not examined in this study, because this requires a slow scanning speed to melt the powder completely and therefore increases the fabrication time and cost. The laser power chosen for producing the 5 samples was therefore varied between 100 and $200 \mathrm{~W}$ (the highest laser power available from the SLM machine). The scanning speeds were chosen over a wide range in order to understand the effect of fast $(727 \mathrm{~mm} / \mathrm{s})$ and slow (98 $\mathrm{mm} / \mathrm{s}$ ) scanning speeds under different laser power settings on the as-fabricated specimens. The hatch spacing $(80 \mu \mathrm{m})$, point

Table 1 SLM process parameters for experiments 1 and 2

\begin{tabular}{lll}
\hline & Parameters & Value \\
\hline Experiment 1 & Laser power $(\mathrm{W})$ & $100 / 125 / 150 / 175 / 200$ \\
& Scanning speed $(\mathrm{mm} / \mathrm{s})$ & $98 / 195 / 381 / 500 / 727$ \\
& Hatch spacing $(\mu \mathrm{m})$ & 80 \\
Experiment 2 & Laser power $(\mathrm{W})$ & 200 \\
& Scanning speed $(\mathrm{mm} / \mathrm{s})$ & $98 / 195 / 381 / 500 / 727$ \\
& Hatch spacing $(\mu \mathrm{m})$ & $40 / 60 / 80 / 100$ \\
\hline
\end{tabular}

distance $(80 \mu \mathrm{m})$, layer thickness $(25 \mu \mathrm{m})$ and scanning strategy were kept constant during experiment 1.

In experiment 2, the hatch spacing and scanning speed parameters were varied from 40 to $100 \mu \mathrm{m}$ and 98 to $727 \mathrm{~mm} / \mathrm{s}$ respectively (see Table 1), while the laser power $(200 \mathrm{~W})$, layer thickness $(25 \mu \mathrm{m})$ and scanning strategy were kept constant. The hatch spacing values were chosen over a range that creates both laser spot overlapping ( 40 and $60 \mu \mathrm{m}$ ) and creates a gap between laser spots $(80$ and $100 \mu \mathrm{m})$, owing to the laser spot size $(75 \mu \mathrm{m})$, in order to see the effect of the distance between spots on the microstructure of the as-fabricated specimens. The layer thickness was kept constant across both experiments due to the fact that using thinner layers can create voids on the deposited layer and can cause a high percentage of the powder to be pushed out of the building zone; however, using thicker layers may create short feeds, which can dramatically decrease the quality of the built part [20]. Similarly, the scanning strategy was kept constant across both experiments due to the small dimensions of the specimens. Although layer thickness and scanning strategy are important parameters for additive manufacturing, these parameters have not been changed during these experiments in order to focus on the effect of the laser power, hatch spacing and scanning speed. A single specimen was produced for each unique pair of parameters. Forty $6 \times 6 \times$ $7 \mathrm{~mm}^{3}$ specimens were produced in total $(25$ for experiment 1 and 15 for experiment 2), using a Renishaw AM250 system (Gloucestershire, UK), which has a modulated ytterbium fibre laser with a wavelength $(\lambda)$ of $1.071 \mu \mathrm{m}$. The diameter of the laser spot is $75 \mu \mathrm{m}$.

Figure 2 a shows a schematic diagram of the manufactured specimens; Fig. 2b, c shows the working principle of the pulsed laser of SLM and related parameters. A meander fillhatch type scanning strategy was used to build the specimens, and the fill-hatch angle was rotated $67^{\circ}$ at each layer, in order to achieve the highest distance between repetitions of the same layer angle (180 layers) (see Fig. 2c). Thus, any possible cracks and defects in the neighbouring layers can be directed through different angles, which can increase the mechanical properties of manufactured specimens.

Figure 3 shows the particle size distribution with the 10,50 and $90 \%$ particle diameters of the volume distribution (Dv) and a scanning electron microscope (SEM) image showing non-spherical powder particles. These non-spherical particles negatively affect the flowability of the powder in the SLM process.

The laser scanning speed $(V)$ was calculated using Eq. 1 (obtained from Renishaw)

$$
V=d_{p} /\left(T_{e}+T_{d}\right)
$$

where $d_{p}$ is the point distance, $T_{e}(800,400,200,150,100 \mu \mathrm{s})$ is the laser exposure time at one point and $T_{d}$ is the laser delay 
Fig. 2 Schematic diagram of the specimen form cross-section view (a), working principle of the pulsed laser (b) and laser scanning strategy of layers (c)

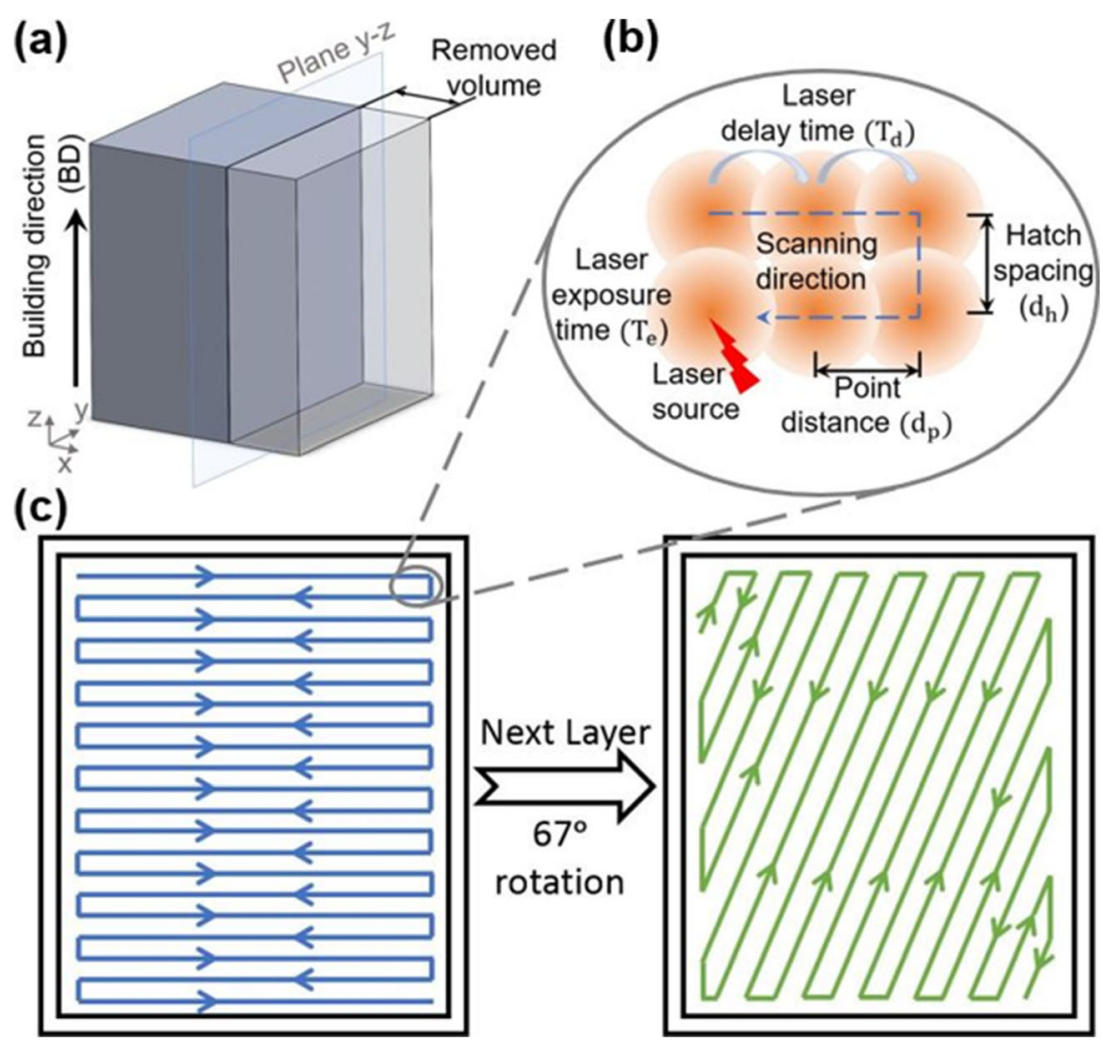

time from one point to another. Laser delay time $(10 \mu \mathrm{s})$ is a constant value for the machine.

The ED was calculated using Eq. 2 [16, 21]:

$\mathrm{ED}=P /\left(V \times d_{h} \times t\right)$ where $P$ is the laser power (from 100 to $200 \mathrm{~W}$ ), $V$ is the scanning speed (from 98 to $727 \mathrm{~mm} / \mathrm{s}$ ), $d_{h}$ is the hatch spacing (from 40 to $100 \mu \mathrm{m}$ ) and $t$ is the layer thickness, set at a constant $25 \mu \mathrm{m}$ in the present study. A wide range of EDs, from 69 to $2041 \mathrm{~J} / \mathrm{mm}^{3}$, have been achieved by changing the laser power, hatch spacing and scanning speed parameters.
Fig. 3 The particle shape and size distribution of the powder

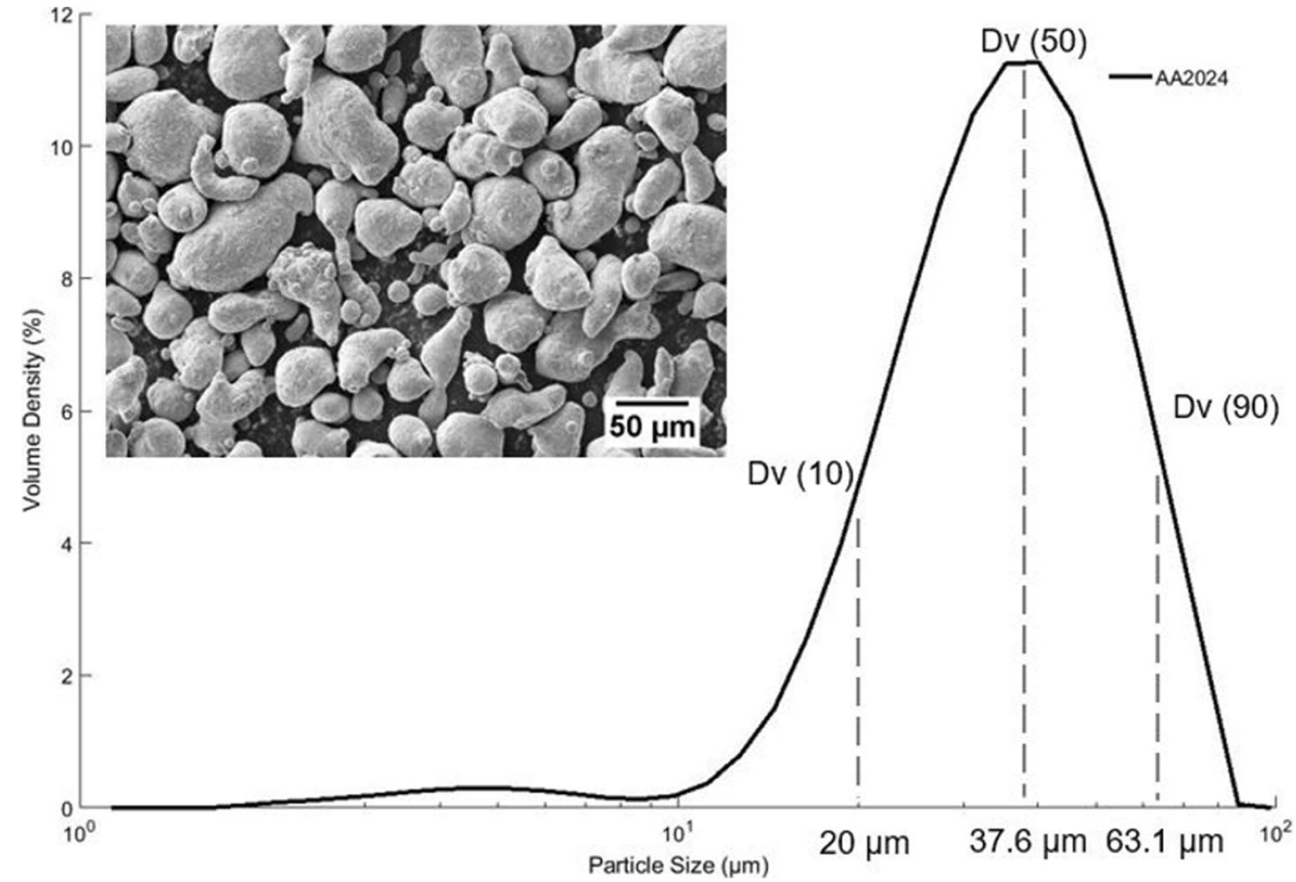


Table 2 Energy densities $\left(\mathrm{J} / \mathrm{mm}^{3}\right)$ of experiments 1 and 2 calculated using Eq. 2

\begin{tabular}{|c|c|c|c|c|c|c|c|c|c|}
\hline & \multicolumn{5}{|c|}{ Experiment 1} & \multicolumn{4}{|l|}{ Experiment 2} \\
\hline & $P=100 \mathrm{~W}$ & $P=125 \mathrm{~W}$ & $P=150 \mathrm{~W}$ & $P=175 \mathrm{~W}$ & $P=200 \mathrm{~W}$ & $d_{\mathrm{h}}=40 \mu \mathrm{m}$ & $d_{\mathrm{h}}=60 \mu \mathrm{m}$ & $d_{\mathrm{h}}=80 \mu \mathrm{m}$ & $d_{\mathrm{h}}=100 \mu \mathrm{m}$ \\
\hline$V=98 \mathrm{~mm} / \mathrm{s}$ & 510 & 638 & 765 & 893 & 1020 & 2041 & 1361 & 1020 & 816 \\
\hline$V=195 \mathrm{~mm} / \mathrm{s}$ & 256 & 321 & 385 & 449 & 513 & 1026 & 684 & 513 & 410 \\
\hline$V=381 \mathrm{~mm} / \mathrm{s}$ & 131 & 164 & 197 & 230 & 262 & 525 & 350 & 262 & 210 \\
\hline$V=500 \mathrm{~mm} / \mathrm{s}$ & 100 & 125 & 150 & 175 & 200 & 400 & 267 & 200 & 160 \\
\hline$V=727 \mathrm{~mm} / \mathrm{s}$ & 69 & 86 & 103 & 120 & 138 & 275 & 183 & 138 & 110 \\
\hline
\end{tabular}

The energy densities used in experiments 1 and 2 are shown in Table 2. The values are calculated using Eq. 2. Hatch spacing kept constant at $80 \mu \mathrm{m}$ during the experiment 1 , and laser power kept constant at $200 \mathrm{~W}$ in experiment 2.

Figure 4 shows the laser spot overlap for different hatch spacing parameters (isometric and top views). If the overlap is too large (i.e. $d_{h}=40 \mu \mathrm{m}$ ), it will re-melt the previous melt pool. If it is too small, or there is no overlap (i.e. $d_{h}=100 \mu \mathrm{m}$ ), unmelted powder and porosity may occur, due to the high distance between each hatch line.

\subsection{Characterisation}

Figure 5 a shows the specimens for experiment 2 during fabrication in the SLM machine. Figure $5 \mathrm{~b}$ shows the manufactured specimens for experiment 1 on the reduced build volume plate. During the experiments, the chosen scanning direction for the specimen parts was from left to right (the opposite direction of the gas flow inside the build chamber), in order to prevent the negative effect of particles spattering from the previous part. The effect of the scan direction and build chamber gas flow on AlSi10Mg alloy samples fabricated using SLM was studied, and it is reported that scanning in the same direction as the gas flow (which carries spattered powder over to the following parts) inhibits the laser beam path, generates oscillations in the melt pool, and embeds spatters inside the following melt pools [22]. Therefore, the second and fourth fabrication layers on the build plate were slightly shifted $(5 \mathrm{~cm})$ in the $+\mathrm{X}$ direction, in order to prevent the parts from short feeding and spatters from previous parts becoming embedded in them. The specimens were mounted into an electrically conductive resin, with each specimen oriented so that the build direction was parallel to the analysing surface (see Fig. 5c, d). First, six different silicon carbide (SiC) grinding sandpapers $(200,400,800,1200,2400$ and 4000 ) were used to grind the hot-mounted specimens at fast rotational speed $(250 \mathrm{rpm})$ of the sanding disk. Then, $5 \mu \mathrm{m}$ and $3 \mu \mathrm{m}$ grain size polishing cloths with diamond suspension and $0.1 \mu \mathrm{m}$ grain size polishing cloths with aluminium oxide lubricant at slow rotational speed $(100 \mathrm{rpm})$ were used to polish the surface of the specimens which meteorological data obtained. The specimens were built on $2 \mathrm{~mm}$ fine supports under an argon gas atmosphere with less than $0.1 \%$ oxygen, in order to minimise oxidation. The Archimedes density (also known as bulk density) of the as-fabricated specimens was determined using a density determination kit, working according to Archimedes' principle, and the relative density was established using an optical microscope (OM) by Nikon eclipse LV-100 (NY, USA) and ImageJ software. Keller's reagent $\left(5 \mathrm{ml} \mathrm{HNO}_{3}, 3 \mathrm{ml} \mathrm{HCl}, 2 \mathrm{ml} \mathrm{HF}\right.$ and $190 \mathrm{ml}$ distilled water) as a metallographic etching compound was applied onto the specimen surface for 30 to $40 \mathrm{~s}$ in order to observe the microstructure of the as-fabricated specimens. A Nova 330/360 IMP Innovatest (Maastricht, the Netherlands) hardness test machine was used to measure Vickers microhardness of the specimens under $200 \mathrm{~g}$ load and $10 \mathrm{~s}$ dwell time. A Zwick/Roell tensile tester with a strain rate of $0.001 \mathrm{~mm} / \mathrm{s}$ was used to carry out the tensile tests, which were conducted at room temperature. Due to the dimensional limitations of the reduced build volume plate in the vertical direction, the tensile
Fig. 4 Schematic diagram of hatch distance $\left(d_{h}\right)$ showing the isometric (3D Gaussian curve) and top view of the laser spot overlapping in the melt pool based on spot size $\left(d_{s}\right)$

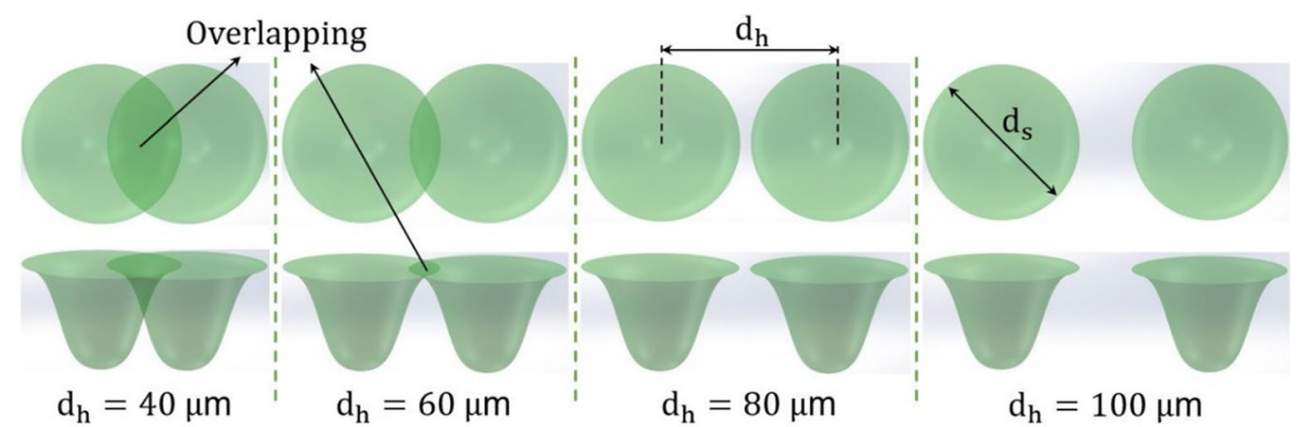


Fig. 5 a The building pattern with specimens for experiment 2 (varying hatch spacing) during fabrication, $\mathbf{b}$ specimens for experiment 1 (varying laser power) after fabrication; specimen holders with specimens of $\mathbf{c}$ different hatch spacings and $\mathbf{d}$ different scanning speeds with $60-\mu \mathrm{m}$ hatch spacing (a)

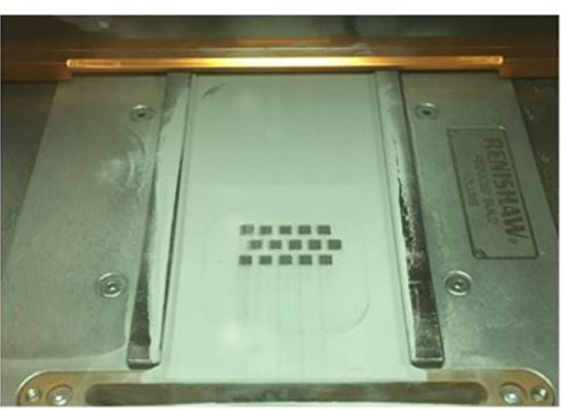

(c)

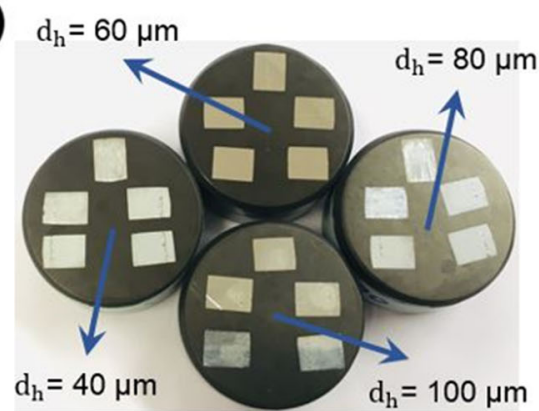

(b)

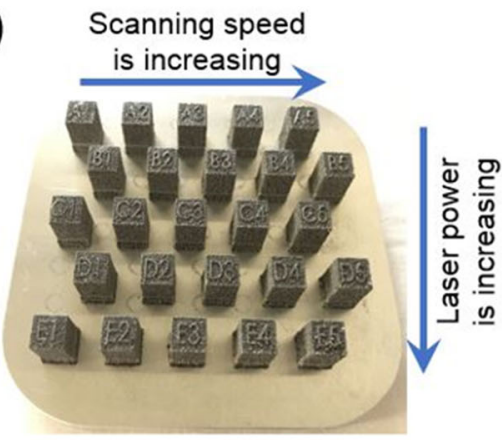

(d)

$$
V=98 \mathrm{~mm} / \mathrm{s}
$$

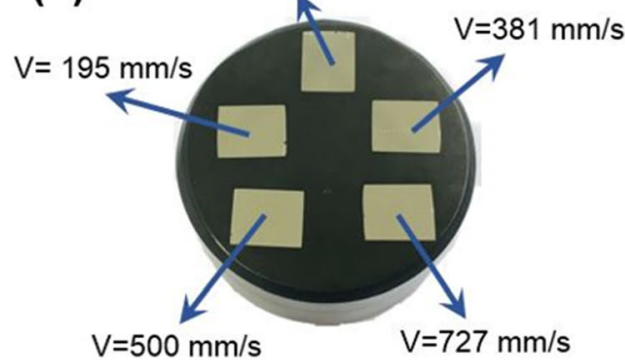

test specimens were fabricated horizontally, according to ASTM-E8 standard, with the layers perpendicular to the loading direction. Previous studies have reported that building direction does not strongly influence or has little effect on the mechanical properties of aluminium alloys [23-26]. For instance, AlSi10Mg alloy specimens were fabricated in both horizontal and vertical directions using SLM, and it is reported that building direction does not strongly influence the creep and tensile properties of the alloy [25]. Similarly, it has been reported that UTS results of the AlCu5MnCdVA alloy fabricated in both directions are nearly the same [26].

\section{Results}

\subsection{Effect on porosity}

A Nikon eclipse LV-100 (NY, USA) optical microscope (× 100 magnification) was used to determine the relative density of as-fabricated specimens based on the observed surface. More than twenty-five different OM images for each specimen (approximately 90\% of the observed surface) were taken to calculate the relative density accurately. ImageJ software was used to calculate the porosity of the surfaces.

Figure 6 shows the relative porosity of as-fabricated specimens produced for experiment 1 and the transition from high relative porosity to an almost crack and pore-free structure. Relative densities higher than $99.5 \%$ are highlighted inside the green discontinuous line, and relative densities lower than 97\% are marked inside the red line. The main issues for the specimens inside the red line are poor wetting, large cracks and pores caused by incomplete fusion (also known as lack of fusion) [21]; however, small gas pores (a common phenomenon for SLM, because of the dissolved gas between the powder particles [27]) are the main problem for the specimens inside the green discontinuous line.

Figure 7 shows specimens produced for experiment 2; the significant effect of varying the hatch spacing and scanning speed on relative porosity can be seen. Slower scanning speeds at 60 - and $80-\mu \mathrm{m}$ hatch space provide less relative porosity on the observed surface. Moreover, the surfaces with the lowest relative porosity were achieved from the slowest scanning speed and $80-\mu \mathrm{m}$ hatch spacing. Porosities which are lower than $1 \%$ are shown inside a red line. Inside this region, small gas pores are the major issue. However, the major issues for the specimens outside the red line are incomplete fusion holes, sharp and hot cracks, un-melted powder and irregularly shaped pores. It has previously been reported that insufficient energy input during the SLM process causes an increase in the discontinuous melt pool and creates incomplete fusion holes [10].

\subsection{Relative and Archimedes densities}

The results of experiments 1 and 2, shown in Figs. 8 and 10, demonstrate that the Archimedes and relative densities are highly dependent on the laser power, scanning speed and hatch spacing parameters.

The effect of the ED on the Archimedes and relative densities is shown in Fig. 8. In experiment 1, the ED varied 


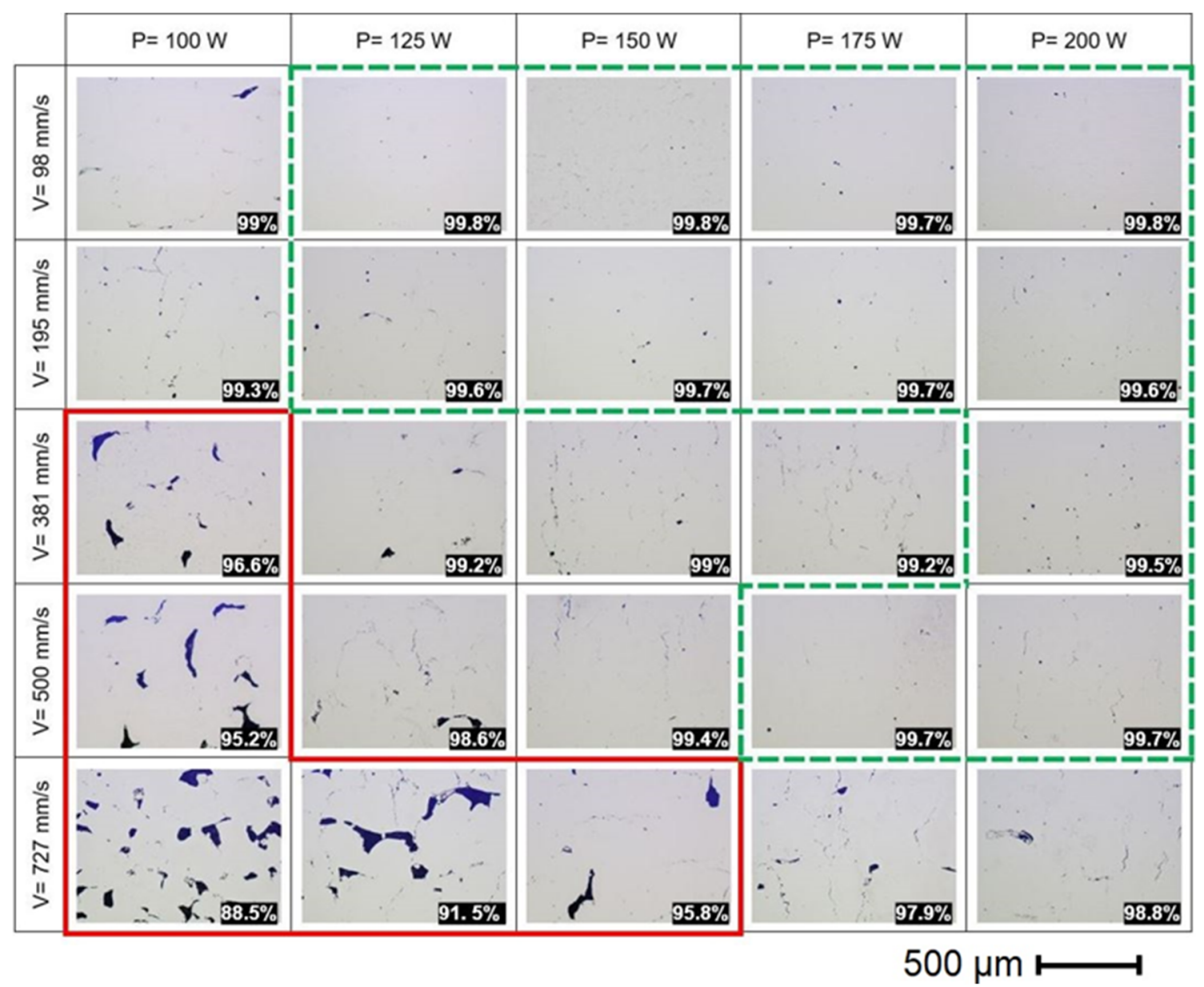

Fig. 6 OM images of as-fabricated specimens from experiment 1 showing the relative porosity plotted against laser power (100 to $200 \mathrm{~W})$ and scanning speed (98 to $727 \mathrm{~mm} / \mathrm{s}$ )

between 69 and $1020\left(\mathrm{~J} / \mathrm{mm}^{3}\right)$ with changes of laser power (from 100 to $200 \mathrm{~W}$ ) and scanning speed (from 98 to $727 \mathrm{~mm} /$ s). The hatch spacing was kept constant at $80 \mu \mathrm{m}$ in experiment 1 in order to understand the effect of the laser power and hatch spacing on Archimedes and relative density. The highest relative density (99.9\%) was achieved at an ED of $759 \mathrm{~J} / \mathrm{mm}^{3}$, and the lowest relative density $(88.5 \%)$ was achieved from the lowest ED $\left(69 \mathrm{~J} / \mathrm{mm}^{3}\right)$. Additionally, the relative density becomes more stable when the ED is above $150 \mathrm{~J} / \mathrm{mm}^{3}$ and increases gradually. On the other hand, the highest Archimedes density (99.5\%) was achieved from the highest ED $\left(1020 \mathrm{~J} / \mathrm{mm}^{3}\right)$. A greater fluctuation in both the Archimedes and relative densities was observed at low ED (see Fig. 8).

The effect of laser power and scanning speed on the relative and Archimedes densities is given in Fig. 9. Both densities show slow improvements at slow scanning speeds (98 and $195 \mathrm{~mm} / \mathrm{s}$ ); however, further increasing the scanning speed $(381,500$ and $727 \mathrm{~mm} / \mathrm{s})$ results in dramatic changes in both densities. This reveals that processing with slow scanning speeds tolerates the negative effect of using low laser power.
In experiment 2, ED varied between 110 and $2041 \mathrm{~J} / \mathrm{mm}^{3}$ (which changes with varying hatch spacing from 40 to $100 \mu \mathrm{m}$ and scanning speed from 98 to $727 \mathrm{~mm} / \mathrm{s}$ ). The laser power remains constant in experiment 2 , at $200 \mathrm{~W}$. The Archimedes and relative densities improve with increasing ED, up to $99.8 \%$ (see Fig. 10). In this research, almost crack and pore-free structures $(0.2 \%$ porosity, using a hatch spacing of $80 \mu \mathrm{m}$ and scanning speed of $98 \mathrm{~mm} / \mathrm{s}$ ) have been achieved at high ED $\left(1020 \mathrm{~J} / \mathrm{mm}^{3}\right)$. Moreover, the Archimedes density greater than $99 \%$ was achieved when the ED was over 684 $\mathrm{J} / \mathrm{mm}^{3}$. The lowest Archimedes density (97.4\%) was obtained at the fastest scanning speed $(727 \mathrm{~mm} / \mathrm{s})$, with $80-\mu \mathrm{m}$ hatch spacing. The relative density shows greater fluctuation around the Archimedes density when the ED is under $410 \mathrm{~J} / \mathrm{mm}^{3}$. However, the two sets of measurements become closer and more stable at the higher EDs, depicting that the layers of the specimens which are fabricated at high ED are more uniform.

The effect of hatch spacing and scanning speed on the Archimedes and relative densities is represented in Fig. 11. The higher densities were achieved using hatch spacing values of 60 and $80 \mu \mathrm{m}$. Closer laser spots (i.e. $40 \mu \mathrm{m}$ ) and farther 


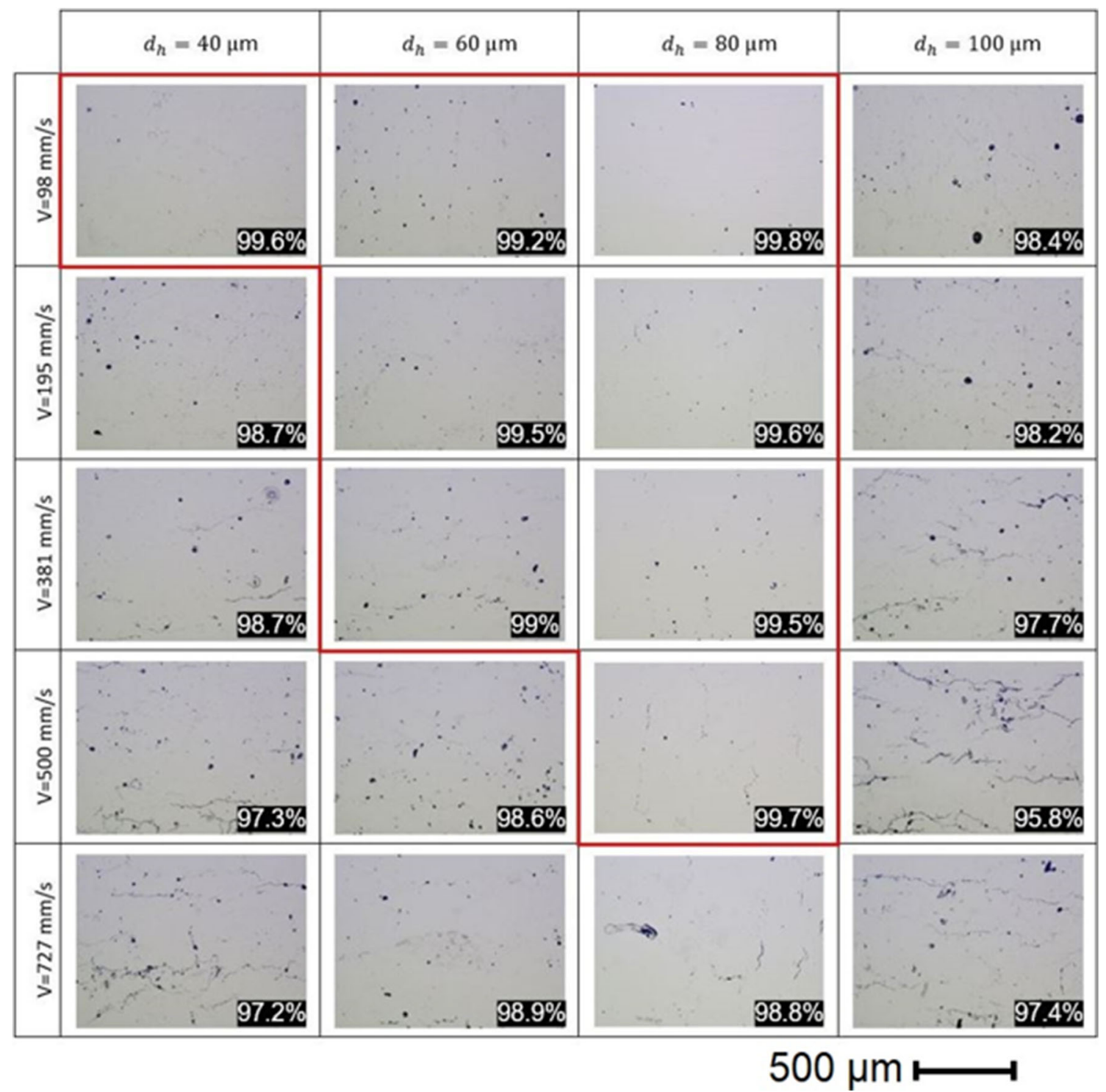

Fig. 7 OM images of specimens from experiment 2 showing the relative porosity of as-fabricated alloy plotted against hatch spacing (40 to $100 \mu \mathrm{m})$ and scanning speed (98 to $727 \mathrm{~mm} / \mathrm{s}$ )

laser spots (i.e. $100 \mu \mathrm{m})$ than the laser focus diameter $(75 \mu \mathrm{m})$ negatively affect the density of the as-fabricated sample.
Similar to the results of experiment 1 , slower scanning speeds tolerate the negative effect of the sub-optimal hatch spacings.
Fig. 8 Archimedes and relative densities of as-fabricated specimens in relation to ED (experiment 1)

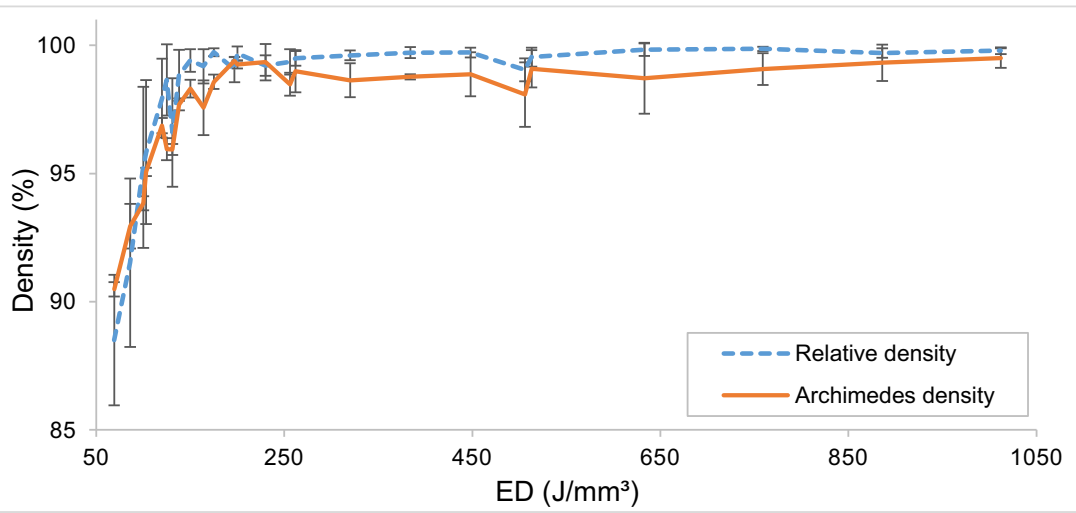


Fig. 9 Archimedes and relative densities of as-fabricated specimens in relation to laser power $(\mathrm{P})$ and scanning speed (V) (experiment 1)

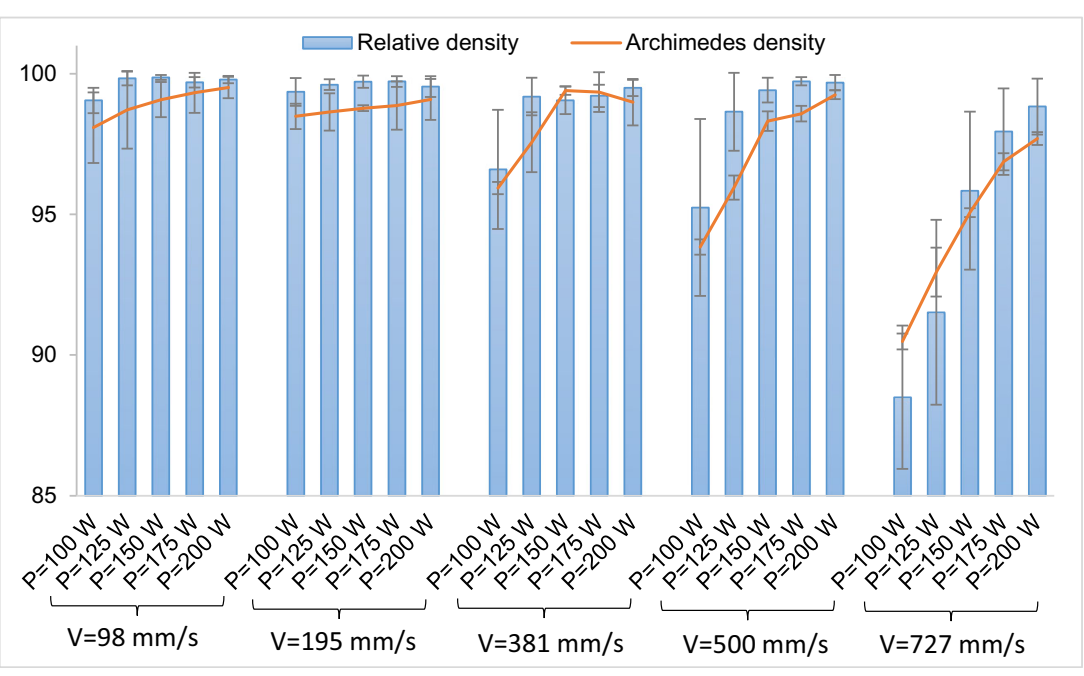

\subsection{Effect on microstructure}

Energy-dispersive X-ray spectroscopy (EDS) results, shown in Fig. 12a-d, show a uniform distribution of $\mathrm{Al}$, $\mathrm{Cu}$ and $\mathrm{Mg}$ elements inside the fracture surface. The $\mathrm{OM}$ images in Fig. 12e-j show the microstructure and melt pool after etching, displayed from higher ED to lower ED. The melt pool, heat affected zone (HAZ), dendrite orientation, cracks, porosities and microstructures of the post-processed specimens are shown. The chemical composition of the melted part and raw AA2024 powder shows an almost identical amount of copper at the observed surface. However, even though medium laser power $(150 \mathrm{~W})$ was used, evaporation was observed for magnesium, reducing from 1.8 to $1.4 \%$, owing to the low boiling point of magnesium [12]. The X-ray spectroscopy process could not detect the other alloying elements owing to the low weight ratio of the elements in the alloy. The build direction of the specimen is parallel to the observed surface. The OM images in Fig. $12 \mathrm{e}-\mathrm{j}$ show that coarse-grained microstructures are prevalent, owing to the high ED caused by high laser power (175 W) and slow scanning speed (195 mm/s) used to produce this specimen. However, when the ED decreases with higher hatch spacing $(100 \mu \mathrm{m})$ and scanning speed (727 $\mathrm{mm} / \mathrm{s}$ ), fine-grained microstructures become more apparent. Due to the fact that different EDs cause different thermal gradients and solidification rates in the melt pool during the cooling, it is strongly influential on the microstructure [28]. The coarse-grained microstructure at the melt pool borders is more visible when manufactured with $60-\mu \mathrm{m}$ hatch spacing, compared with $100 \mu \mathrm{m}$, even though the scanning speed and laser power are the same (see Fig. 12h and $\mathrm{j}$ ). Examining the HAZ also shows the presence of some fine-grained microstructures, with gradients from finegrained to coarse-grained microstructures. Moreover, solidification cracks (which is the foremost problem of the alloying elements for SLM production) occur inside the melt pool. It is also observed that the melt pool depths of the specimens are non-uniform.

SEM images comparing three specimens produced with different laser power $(125,175 \mathrm{~W}$ and $200 \mathrm{~W})$ and scanning speed $(98,381$ and $500 \mathrm{~mm} / \mathrm{s})$ settings, at a constant hatch spacing $(80 \mu \mathrm{m})$, are presented in Fig. 13, showing the microstructure, melt pool, solidification boundary, re-melt boundary and columnar dendrites of the as-fabricated specimens. Several microcracks, solidification cracking, microvoids,
Fig. 10 The Archimedes and relative density of as-fabricated specimens in relation to the $\mathrm{ED}$ (experiment 2)

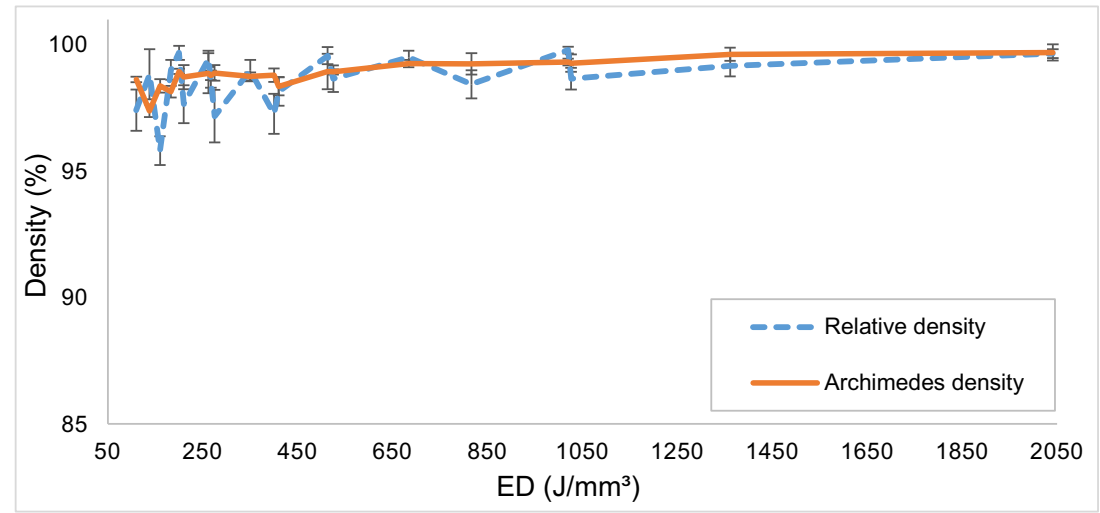


Fig. 11 The Archimedes and relative density of as-fabricated specimens in relation to the hatch spacing $\left(d_{\mathrm{h}}\right)$ and scanning speed (V) (experiment 2)

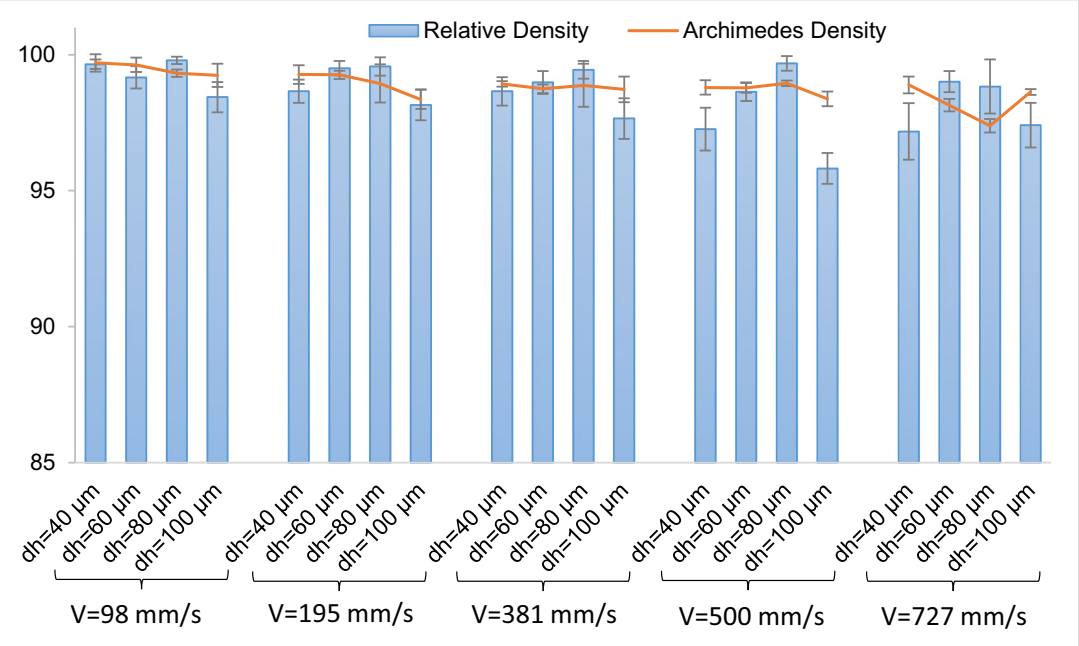

small balling porosities and boundary cracks are shown in Fig. 13. Moreover, Fig. 13f shows that microcracks have grown throughout the melt pool boundary. In the same way, it has previously been reported that small amounts of unsolidified liquid between the melt pool edges form films which keep the pools from bonding together in the final stage of solidification and eventuate in boundary cracks [29]. Additionally, the dendrite orientation aligns towards the melt pool centre.

Examples of specimens produced with low ED, owing to fast scanning speeds, are shown in Fig. 14. Low ED, fast scanning speed and incomplete fusion cause unmelted powder and large cracks to form inside the structure, even though laser power is sufficiently high.

\subsection{Effect on microhardness}

Fig. 15 and Fig. 16 show that the microhardness and ED are inversely proportional. Increasing the ED results in a gradual reduction of the microhardness.

Figure 15 shows the effect of ED (in experiment 1) on the Vickers microhardness under a $200-\mathrm{g}$ load $\left(\mathrm{HV}_{0.2}\right)$. With increasing ED, the microhardness gradually decreases, except for some small fluctuations. The highest microhardness (116 $\mathrm{HV}_{0.2}$ ) was achieved from one of the lowest EDs $\left(100 \mathrm{~J} / \mathrm{mm}^{3}\right)$, and the lowest microhardness $\left(97.5 \mathrm{HV}_{0.2}\right)$ was obtained from one of the highest EDs $\left(759 \mathrm{~J} / \mathrm{mm}^{3}\right)$. Additionally, microhardness is inversely proportional to the relative and Archimedes density results in experiment 1 (see Fig. 8). High densities were achieved at high EDs, which produce microhardness of a lower value. Moreover, the pattern of fluctuations in the results is identical to those seen in the results for Archimedes and relative densities. At higher EDs, the fluctuations become smoother than at low EDs.

Similarly to experiment 1 (Fig. 15), the microhardness results of experiment 2 also show fluctuations at low EDs (Fig.
16). When the ED is increased, the microhardness becomes more stable, and the hardness progressively decreases. The highest microhardness obtained when varying the hatch spacing $\left(115.5 \mathrm{HV}_{0.2}\right)$ was obtained at the lowest ED. Similarly, the lowest microhardness $\left(87.8 \mathrm{HV}_{0.2}\right)$ is achieved at the highest ED. The pattern of fluctuation seen in experiment 2 is identical to those seen in experiment 1. Sharp fluctuations are apparent at low EDs and become smoother at higher EDs.

The microhardness test indentation dimensions, depth and angle on the measured surface are depicted in Fig. 17. Polished cross-section surfaces, which are parallel to build direction of the specimens, were measured in order to examine the microhardness of different layers. The microhardness machine calculates the Vickers microhardness (HV) value by Eq. 3 (ASTM E92-16):

$\mathrm{HV}=1854.4 \times P /\left(d_{a}\right) 2$

where $P$ is applied load (200 kgf) on test specimens and $d_{a}$ is the arithmetic mean of $d_{1}$ and $d_{2}$ (Fig. 17). During the experiment, $d_{1}$ and $d_{2}$ showed a variety between 54.12 and 65.5 $\mu \mathrm{m}$.

\subsection{Effect on tensile strength}

The mechanical and microstructural properties of tensile test specimens are shown in Fig. 18. The ultimate tensile strength (UTS) (145 MPa) and strain are shown in the stress-strain curves (Fig. 18). The figure shows that the tensile specimens fail before plastic deformation occurs, because of the brittle structure.

Further tensile test specimens were fabricated following the evaluation of experiment 2 . The optimum parameters (60 and 
Fig. 12 Uniform distribution of $\mathrm{Al}, \mathrm{Cu}$ and $\mathrm{Mg}$ elements via $\mathrm{X}$ ray spectroscopy (EDS) (a-d) and OM images showing the microstructure $(\mathbf{e}-\mathbf{j})$

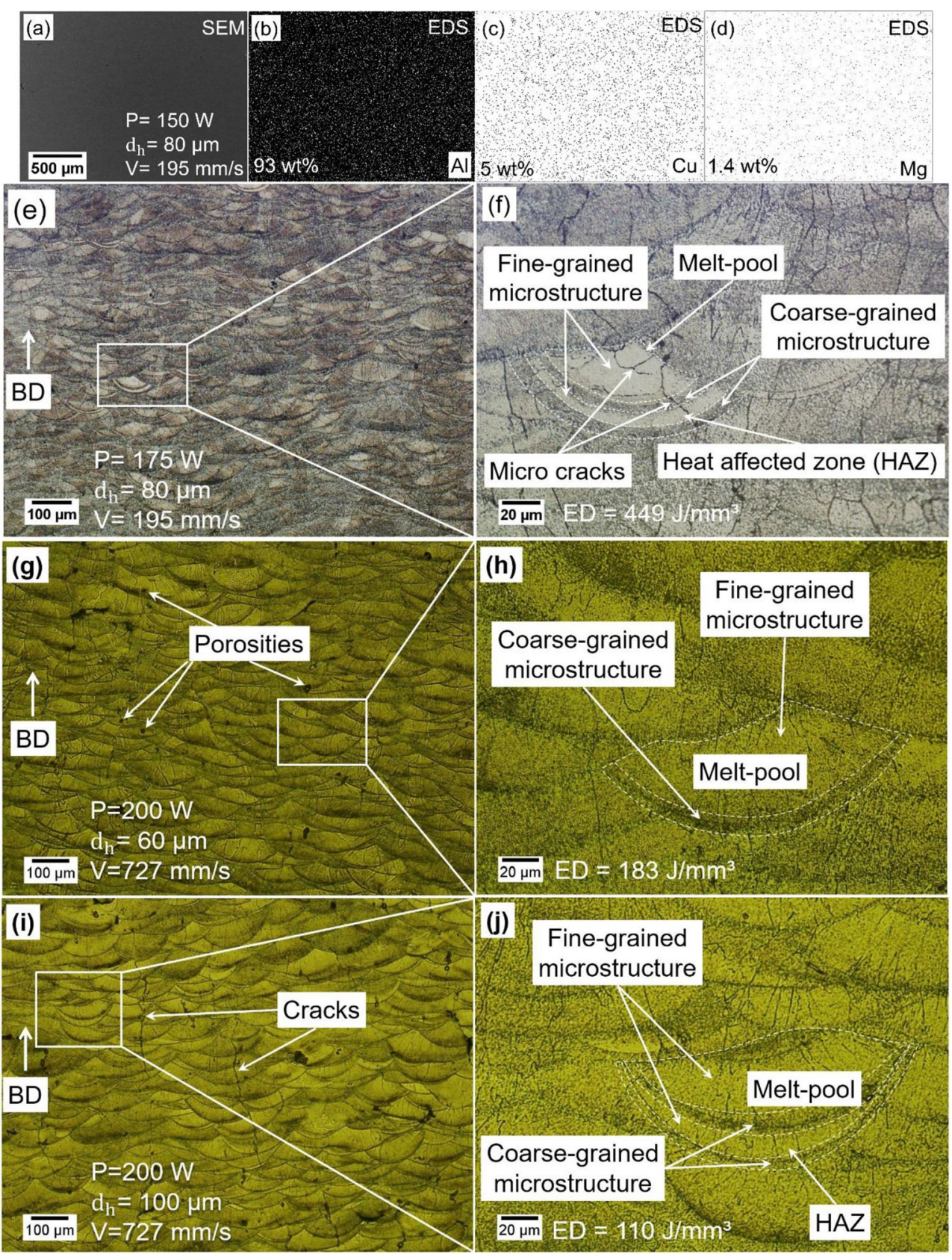

$80-\mu \mathrm{m}$ hatch spacing, with $98 \mathrm{~mm} / \mathrm{s}$ scanning speed) were again chosen based on the highest relative and Archimedes densities obtained from the cubic specimens. Fig. 19 shows the tensile test results of the as-fabricated specimens (present study) and as-cast AA2024 alloy [17]. It is seen from Fig. 19 that the as-fabricated alloy specimens have approximately $20 \%$ less strength than the as-cast alloy.

Figure 20 indicates the dimensions and the fracture surface of the round tensile test specimens. The parameters, which achieved the highest relative density (99.9\%) in experiment 1 (with $150 \mathrm{~W}$ laser power, $80-\mu \mathrm{m}$ hatch spacing and $98 \mathrm{~mm} / \mathrm{s}$ scanning speed), were used to fabricate the test specimens. Even though a relative density of $99.9 \%$ was achieved in the cubic specimens, the tensile test fracture surface has some unmelted powder holes, cracks, porosities and unmelted powder particles, which led to a brittle failure (Fig. 20(c-1, c-2, c$3)$ ). Furthermore, the crack initiation started from the site of unmelted powder particles and holes.

\section{Discussion}

The Archimedes and relative densities of as-fabricated specimens are directly proportional with the ED used in manufacturing, due to the fact that high power, low hatch distance and slow scanning speed create a high melt pool 
Fig. 13 SEM images showing the microstructure, melt pool, solidification boundary, re-melt boundary and columnar dendrites of the as-fabricated specimens
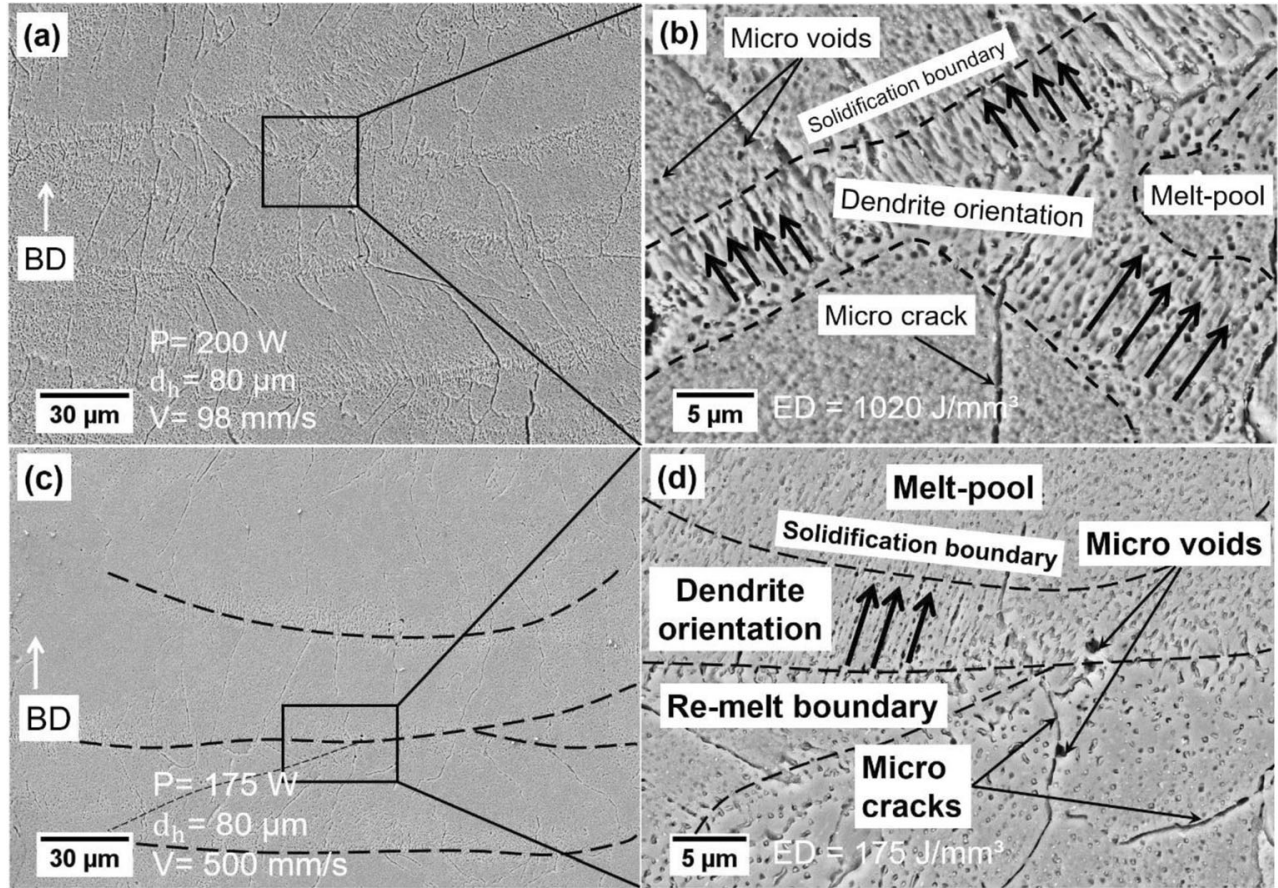

Re-melt boundary

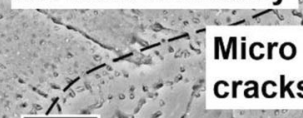

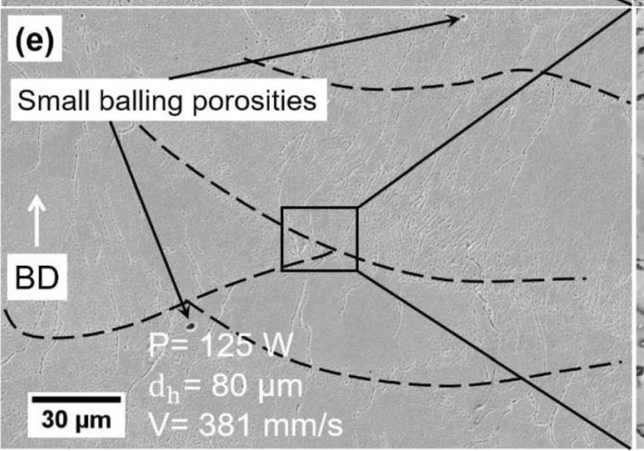

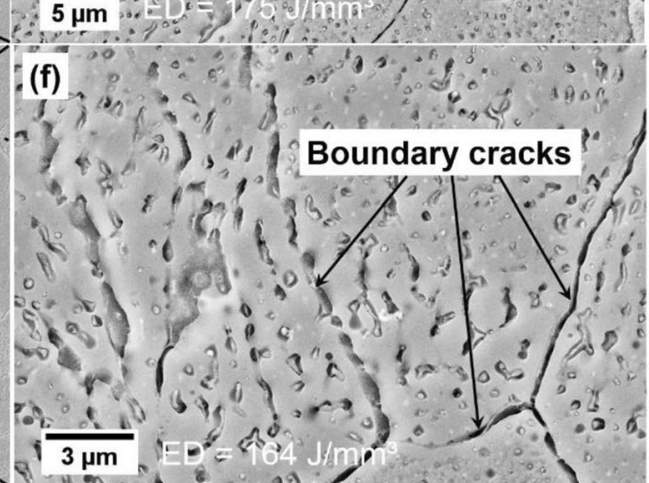

temperature. Additionally, the high temperature reduces the viscosity of the melted metal and results in better filling of the possible cracks or pores, which correlates with this result. Similarly, it has previously been observed that high ED results in a high level of liquid phase accompanied by a slow solidification time, which lowers the viscosity of the liquid [30,
31]. Thus, more neighbouring layers are positively affected, because the high ED will increase the number of penetrated layers. It was also reported that a high melt pool temperature can decrease the surface tension and improve the wettability of the liquid metal as a result of the low cooling rate and better Marangoni flow [30]. Moreover, both the Archimedes density
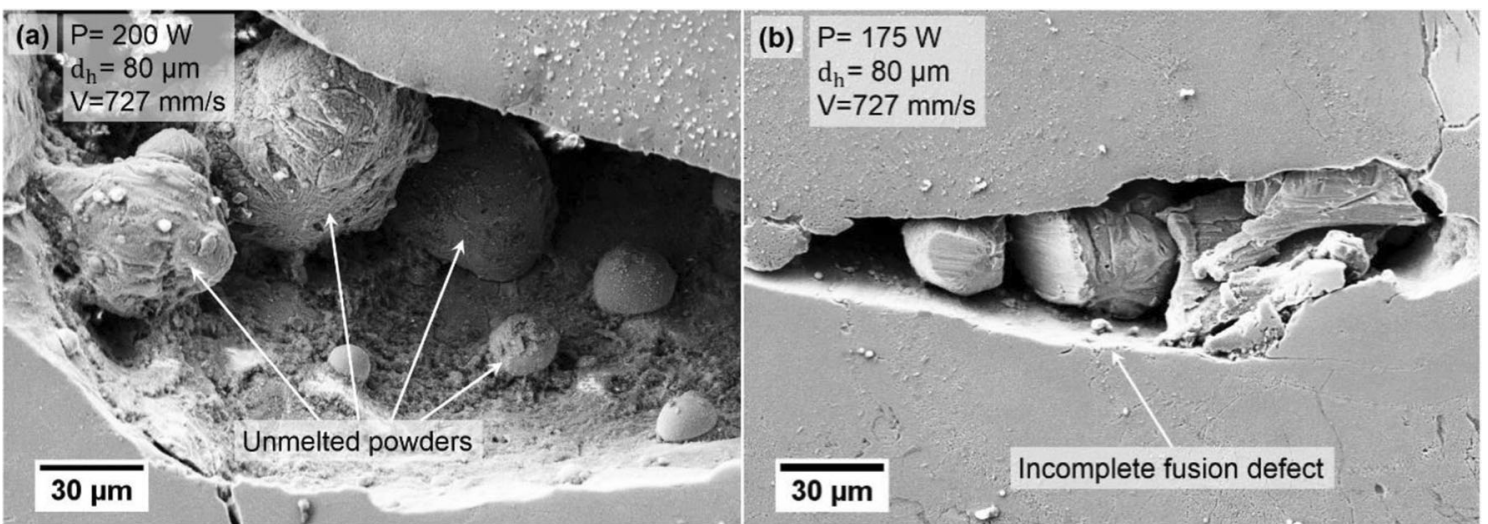

Fig. 14 SEM images of unsuccessful fabrication showing (a) unmelted powders and (b) incomplete fusion defect owing to low ED 
Fig. 15 Vickers microhardness $\left(\mathrm{HV}_{0.2}\right)$ of as-fabricated specimens in relation to ED (experiment 1)

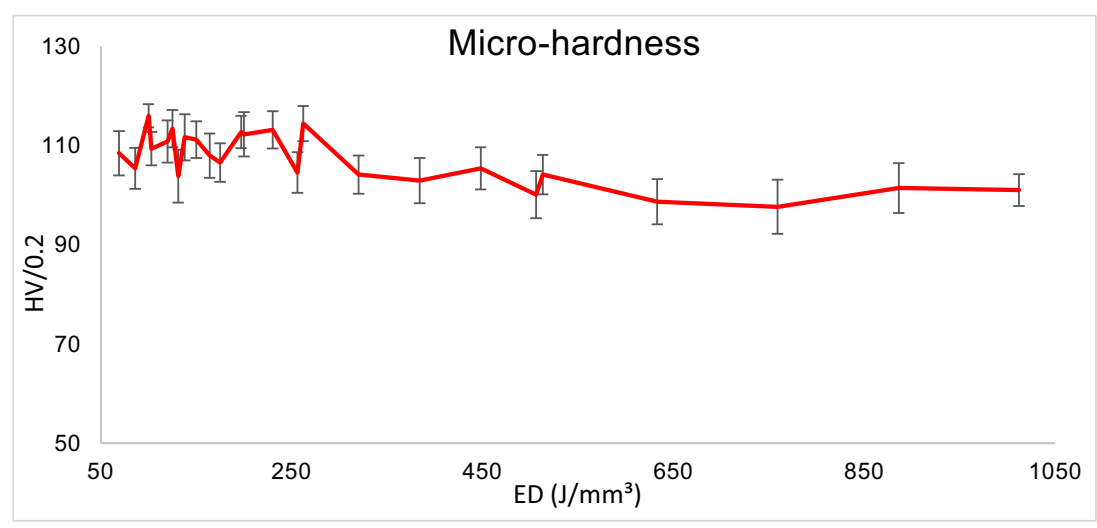

and the relative density have fluctuations at low ED, and the difference between the densities recorded with the two measurement methods at low ED is larger than at high ED. This is because low ED can cause large cracks to form in some layers, causing inconsistencies in the structure, and therefore variation in the measurements. On the other hand, using a slow scanning speed can partially reduce the negative effect of the laser power and hatch spacing settings. This is because slower scanning speeds at constant laser power allow the powder to be melted more effectively than at faster scanning speeds, owing to the higher ED.

When examining the microstructure, coarse-grained microstructures have been observed at higher EDs, with lower EDs creating fine-grained microstructures. The reason for this difference is that higher ED increases the temperature of the melt pool, thus decreasing the cooling rate. A slower cooling rate allows more grain growth, increasing the coarse-grained microstructure formation [32]. It has previously been observed that thermal gradients, which are created by using different hatch spacing parameters, can result in the formation of these different microstructures and that both fine-grained and coarse-grained microstructures can be found around the HAZ in a single sample [33]. Owing to these thermal gradients, columnar grains can form during the solidification process, which then grow from the top to the bottom of the melt pool [17]. Furthermore, it has been reported that due to the Gaussian-distributed heat flux during laser irradiation, the temperature at the central point of the melt pool is much higher than that at the boundary [34]. The rate of solidification at the midpoint of the melt pool is therefore more rapid than at the boundary regions [34]. These thermal gradients will also lead to surface tension gradients, which cause a Marangoni flow from regions of low to high surface tension. This will result in a reduction of the temperature in the boundary regions of the melt pool, since there is an inversely proportional relationship between surface tension and temperature [35]. As above, it is again reported that large thermal gradients were formed inside the melt pool because of the Gaussian heat flux distribution [35]. Additionally, it has been reported that coarse-grained microstructures generally form at the bottom of the melt pool, due to the thermal gradients and the subsequent differences in solidification rates between the top and the bottom of the melt pool [36]. The HAZ can also cause an accumulation of coarsegrained microstructures at the bottom region of the melt pool [36]. Moreover, gradients from fine-grained to coarse-grained microstructures become more distinct at high EDs, owing to the high thermal gradient through the melt pool. Hence, the boundaries of the different microstructures in the melt pool become more obvious. Similarly, the slower cooling rate at the boundary regions of the melt pool produces larger grains, which explains the coarse dendritic microstructure [37].

An inversely proportional relationship between the microhardness and ED has been determined in both experiments. This can be explained by the difference in the microstructure.
Fig. 16 Vickers microhardness $\left(\mathrm{HV}_{0.2}\right)$ of as-fabricated specimens in relation to ED (experiment 2)

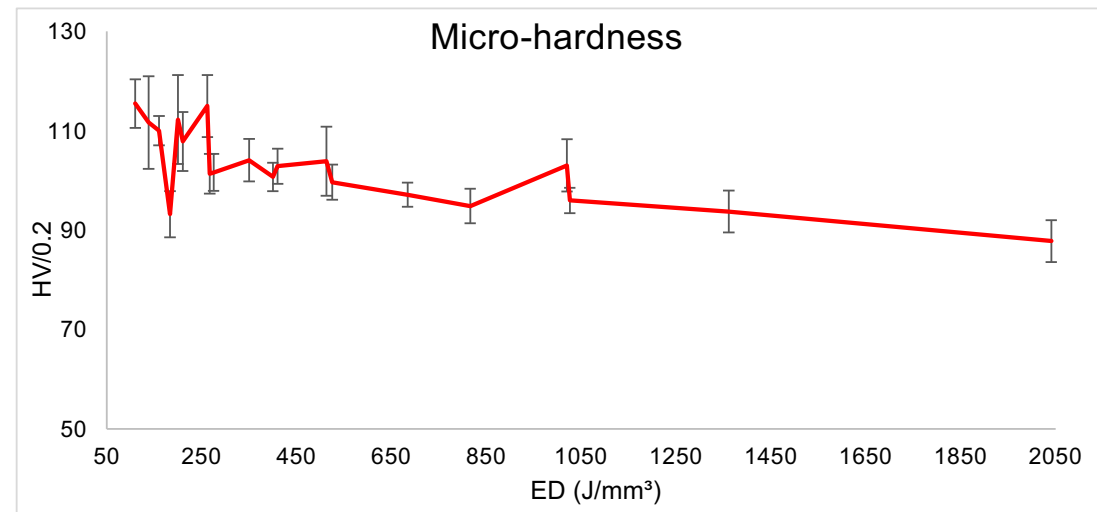




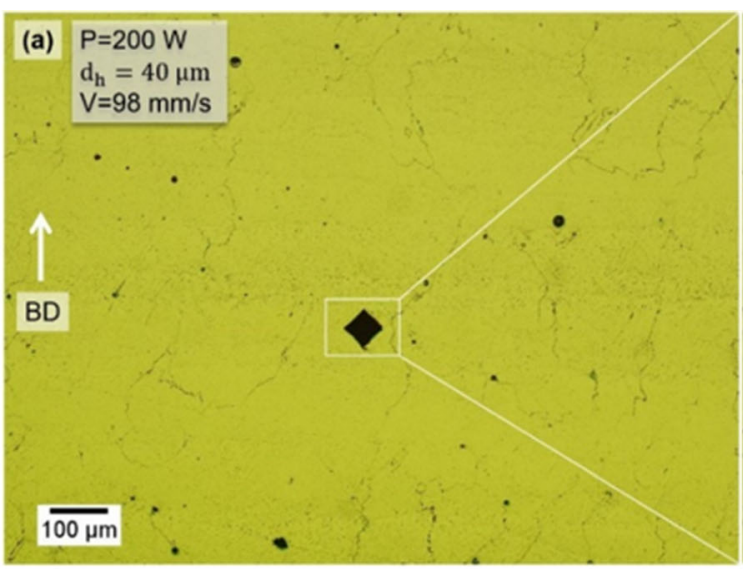

(c)

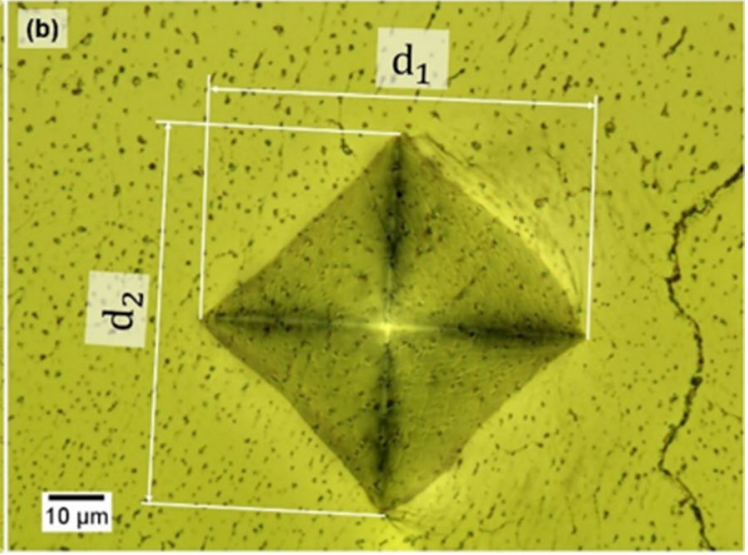

$100^{\circ}$

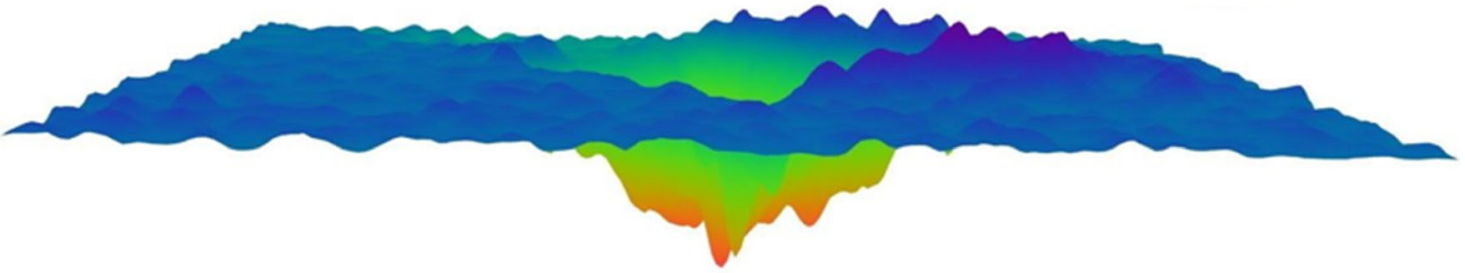
$9 \mu \mathrm{m}$
$7 \mu \mathrm{m}$
$5 \mu \mathrm{m}$
$3 \mu \mathrm{m}$
$1 \mu \mathrm{m}$

Fig. 17 OM micrographs showing $\mathbf{a}, \mathbf{b}$ microhardness indentation dimensions and $\mathbf{c}$ dept and angle of as-fabricated specimens

High energy in the melt pool area increases the solidification time, the temperature of melted material and size of the melt pool [27]. However, high temperatures also result in a slow cooling rate at the solidification interface, which generates a coarse-grained microstructure. Contrary to this, using a low ED increases the cooling rate and creates a fine-grained microstructure, which restricts the dislocation movement [38]. Due to this limited dislocation movement, the microhardness shows a gradual increase at low EDs. Similarly, low microhardness at high ED has been previously reported in another

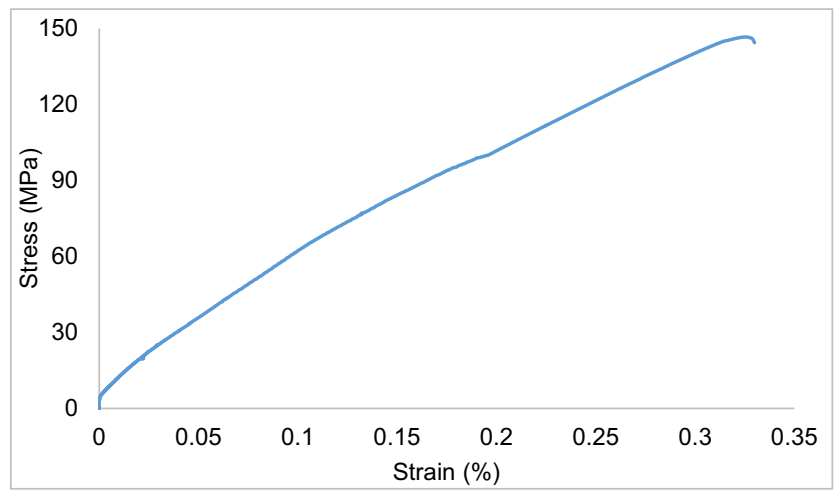

Fig. 18 Tensile strength vs strain curve of the as-fabricated specimen fabricated using $150 \mathrm{~W}$ laser power, $80-\mu \mathrm{m}$ hatch spacing and $98 \mathrm{~mm} / \mathrm{s}$ scanning speed showing the brittle failure of the specimens study [39]. Microhardness of Sc- and Zr-modified the aluminium 7075 alloy firstly increased and then decreased with increasing ED owing to the grain size and chemical composition of the alloy. Additionally, it has been stated that the reduction of the magnesium with increasing temperature of melt pool and ED may reduce the microhardness of the as-fabricated specimens [40]. The reduction of the weight ratio of magnesium is also observed in the present study. The maximum microhardness achieved is approximately $45 \%$ higher than as-cast AA2024 alloy but $17 \%$ lower than wrought AA2024-T6. However, SLM provides 26\% higher microhardness in comparison with the as-cast alloy, but $28 \%$ lower than wrought alloy at the optimum parameter (Table 3 ). The increase in microhardness, when compared with the as-cast alloy, may be due to the limitation of dislocation and movement by the fine-grained microstructures produced by SLM [41]; higher dislocation density restricts slip along the grain boundaries, restricting deformation and increasing the strength. It is also noted that, although the diagonal angle of microhardness indentation tool is $136^{\circ}$, the measured angle after the test is completed is $100^{\circ}$ (Fig. 17c). This is because the as-fabricated specimen deforms elastically during the dwell time and retracts after the microhardness indentation tool is removed. Similarly in another study, the diagonal angle of the indentation trace of the Vickers indentation tool on the 
Fig. 19 Tensile testing of asfabricated AA2024 (fabricated using 60 - and $80-\mu \mathrm{m}$ hatch spacing and $98 \mathrm{~mm} / \mathrm{s}$ scanning speed) in the present study and as-cast alloy in [17] showing UTS

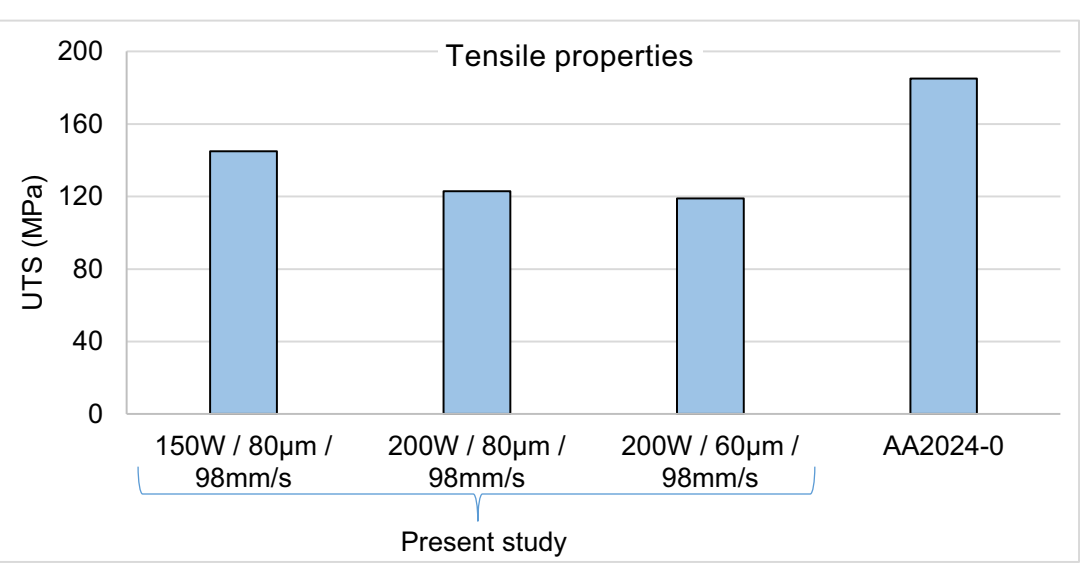

observed surface of the $\mathrm{Al}(\mathrm{Si})-\mathrm{Cu}-\mathrm{Co}$ alloy after the load was measured as approximately $75^{\circ}[42]$.

The UTS of as-fabricated AA2024, produced by SLM (145 $\mathrm{MPa}$ ) in the present work, is lower than as-cast AA2024 (185 $\mathrm{MPa}$ ), as expected, because of the high relative crack sensitivity of the alloy during the welding process. Unmelted powder particles on the surface of the tensile specimens may also contribute to their brittleness. Comparably, the effect of specimen size on porosity of as-fabricated AA2618 (which has a similar weight ratio of alloying elements to AA2024), manufactured using SLM, may give an indication of the effect of the fabricated component size on priority [43]. It has been reported that when the fabricated specimen size is increased from $5 \times 5 \times 5$ to $13 \times 13 \times 5 \mathrm{~mm}^{3}$, the relative porosity
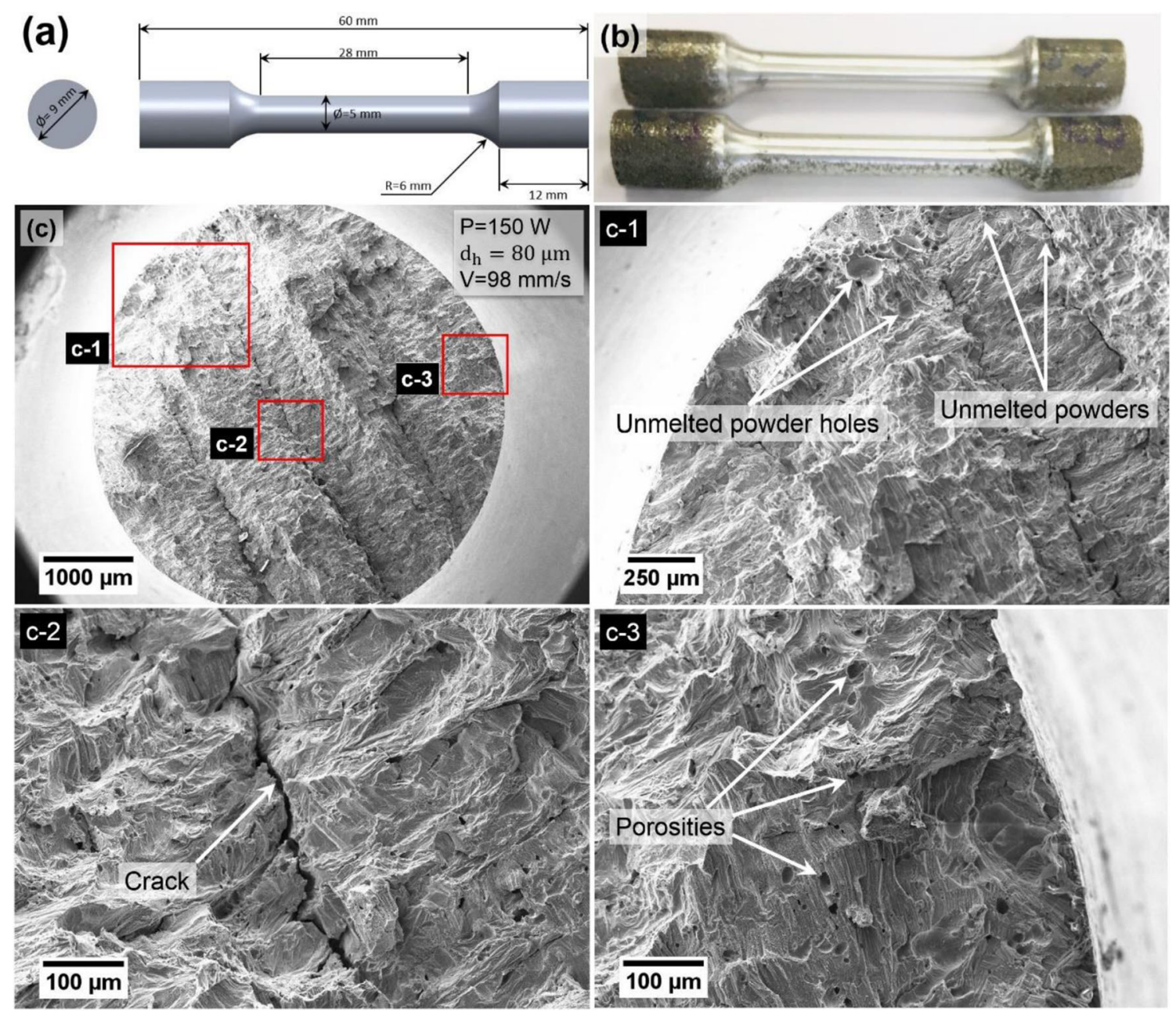

Fig. 20 Dimensions of as-fabricated tensile testing specimens ((a), (b)) and SEM images showing the fracture surface ((c-1), (c-2), (c-3)) 
Table 3 Microhardness results of the alloy under different manufacturing methods

\begin{tabular}{llll}
\hline Metal matrix & Microhardness (HV) & Method & Ref. \\
\hline AA2024 & 116 (maximum) & SLM & Present study \\
& 101 (optimum) & SLM & \\
AA2024-0 & 80 & As-cast & {$[17]$} \\
AA2024-T6 & $135-145$ & Wrought & \\
\hline
\end{tabular}

dramatically increases from 0.03 to $5.95 \%$ [43]. It has also been shown that, for as-fabricated AA2618 series alloys, different tensile test results were observed for different processing strategies (i.e. built on supports, built on the plate, meander, chessboard, hull and core) and different fabrication techniques (i.e. SLM vs extruded material) [43]. It is discussed that, while defects in the structure are reduced substantially, the cracks on the interface are a major restriction in achieving a high mechanical strength for the alloy [43]. Hence, the high crack susceptibility of the alloy, especially for larger parts, makes the tensile test specimen more brittle.

In our study, even though a relative density of $99.9 \%$ was achieved in the cubic samples when using the optimum parameters, unmelted powder holes, lack-of-fusion porosities and gas porosity have been observed on the fracture surface of the tensile test specimens (as shown in Fig. 20). It has also been reported that higher laser energy, along with high scanning speed, causes an increase in the residual stress in both the $x$-direction and $y$-direction of the built specimen [31]. Hence, the mechanical properties of the as-fabricated tensile specimens may be affected dramatically. Another possible cause of the low mechanical properties of the alloy may be an oxide film around the melt pool. Difficulties in fabricating aluminium alloys using SLM have been previously studied, and it has been reported that the formation of a thin oxide film happens around melt pool, upper and lower surfaces in every layer, and cracks and pores are formed when several oxide films meet at one region [44]. It was concluded with that formation of the oxide film can be eliminated by producing $100 \%$ dense part which is technically impossible for aluminium fabricated using SLM [44].

\section{Conclusions}

This study investigates the effect of laser power, hatch spacing and scanning speed on the mechanical properties and microstructure of as-fabricated AA2024 alloy manufactured using SLM. A wide range of energy densities, which are obtained by varying the laser power $(100,125,150,175$ and $200 \mathrm{~W})$, scanning speed $(98,195,381,500$ and $727 \mathrm{~mm} / \mathrm{s})$ and hatch spacing $(40,60,80$ and $100 \mu \mathrm{m})$, are investigated for the processing of this alloy. Other parameters of the SLM process were kept constant during the experimental work to allow comparisons. The Archimedes density, relative density, microhardness and tensile strength were studied in order to determine the effect of varying ED. The following conclusions are drawn from the experimental results.

(1) The highest relative density (99.9\%) was achieved using a $98 \mathrm{~mm} / \mathrm{s}$ scanning speed, $80-\mu \mathrm{m}$ hatch spacing and $150 \mathrm{~W}$ laser power (rather than $200 \mathrm{~W}$ laser power, which produced a density of $99.8 \%$ ). However, the highest Archimedes density (99.7\%) was achieved from the highest laser power $(200 \mathrm{~W})$ and the slowest scanning speed $(98 \mathrm{~mm} / \mathrm{s})$ at a $40-\mu \mathrm{m}$ hatch spacing.

(2) The major phenomena when using EDs lower than 130 $\mathrm{J} / \mathrm{mm}^{3}$ are unmelted powder and large cracks forming inside the structure, due to incomplete fusion. The foremost issues for EDs higher than $300 \mathrm{~J} / \mathrm{mm}^{3}$ are microcracks and small gas pores (due to air remaining between the prepared powder particles), inside the melt pool during the melting process.

(3) Slower scanning speeds provide higher Archimedes and relative densities at constant laser power and hatch spacing. The negative effect of low laser power may partially be eliminated by reducing the scanning speed.

(4) Both Archimedes and relative density results at higher EDs show similarities; however, high fluctuations were observed at lower energy densities due to the nonuniform layers of the as-fabricated specimens and the measurement technique for relative density, which utterly depends on the nature of the observed surface.

(5) The highest microhardness $\left(115.5 \mathrm{HV}_{0.2}\right)$ was achieved from the lowest ED. Correlatively, the lowest microhardness was achieved from the highest ED. The reason for this inversely proportional relationship is that low ED provides low temperatures in the melt pool, a high cooling rate, and produces a fine-grained microstructure, which restricts dislocation movement in the structure and hence increases the microhardness.

(6) Tensile testing results and the analysis of the fracture surface reveal that solidification cracking plays a significant role in the strength of larger parts made from these alloys. The maximum UTS was measured as $145 \mathrm{MPa}$ for the tensile test specimen manufactured with $150 \mathrm{~W}$ laser power and $98 \mathrm{~mm} / \mathrm{s}$ scanning speed at $80-\mu \mathrm{m}$ hatch spacing. SEM images show that unmelted powder is observed on the fracture surface of the tensile test specimen, contrary to the results obtained from the $6 \times 6 \times 7$ $\mathrm{mm}^{3}$ specimens. The crack initiation started from the edge of the tensile specimen on which unmelted powder occurred, due to the incomplete fusion.

These results indicate that the processing parameters, especially laser power, hatch spacing and scanning speed of the 
SLM process, have a substantial effect on the properties of the as-fabricated specimens. As a result of the presented study, 60- and $80-\mu \mathrm{m}$ hatch spacing and $98 \mathrm{~mm} / \mathrm{s}$ scanning speed under $200 \mathrm{~W}$ laser power and $25-\mu \mathrm{m}$ layer thickness are recommended for the fabrication of small components. Nevertheless, solidification cracking creates some limitations in producing larger parts from this alloy. Further study might, therefore, be required in order to investigate whether further improvements to the mechanical properties of the alloy can be achieved with additional reinforcing elements. Some materials (i.e. $\mathrm{Al} 2 \mathrm{O} 3, \mathrm{SiC}, \mathrm{TiN}, \mathrm{BN}, \mathrm{WC}, \mathrm{B} 4 \mathrm{C}$ and some carbon-based allotropes including graphene) might improve mechanical properties of the alloy. Carbon-based allotropes, in particular, have a positive effect on mechanical properties of $2 \mathrm{xxx}$ series of Al alloy.

\section{Authors' contributions Not applicable}

Funding This research is supported by the ministry of national education of Turkey and ASTUTE 2020 (Advanced Sustainable Manufacturing Technologies). This operation, supporting manufacturing companies across Wales, has been part-funded by the European Regional Development Fund through the Welsh Government and the participating Higher Education Institutions.

Data availability Not applicable

\section{Compliance with ethical standards}

\section{Competing interests Not applicable}

Ethical approval Not applicable

Consent to participate Not applicable

Consent to publish Not applicable

Code availability Not applicable

Open Access This article is licensed under a Creative Commons Attribution 4.0 International License, which permits use, sharing, adaptation, distribution and reproduction in any medium or format, as long as you give appropriate credit to the original author(s) and the source, provide a link to the Creative Commons licence, and indicate if changes were made. The images or other third party material in this article are included in the article's Creative Commons licence, unless indicated otherwise in a credit line to the material. If material is not included in the article's Creative Commons licence and your intended use is not permitted by statutory regulation or exceeds the permitted use, you will need to obtain permission directly from the copyright holder. To view a copy of this licence, visit http://creativecommons.org/licenses/by/4.0/.

\section{References}

1. Dursun T, Soutis C (2014) Recent developments in advanced aircraft aluminium alloys. Mater Des 56:862-871
2. Patil DC, Venkateswarlu K, Kori SA, Das G, Das M, Alhajeri SN, Langdon TG (2014) Mechanical property evaluation of an Al-2024 alloy subjected to HPT processing. Mater Sci Eng 63(012085):1-9

3. Hu Z, Chen F, Xu J, Nian Q, Lin D, Chen C, Zhu X, Chen Y, Zhang M (2018) 3D printing graphene-aluminum nanocomposites. J Alloys Compd 746:269-276

4. Pourmand NS, Asgharzadeh H (2019) Aluminum matrix composites reinforced with graphene: a review on production, microstructure, and properties. Crit Rev Solid State Mater Sci:1-49

5. Ngo TD, Kashani A, Imbalzano G, Nguyen KTQ, Hui D (2018) Additive manufacturing (3D printing): a review of materials, methods, applications and challenges. Compos Part B 143:172-196

6. NIU X, SINGH S, GARG A, SINGH H, PANDA B, PENG X, ZHANG Q (2019) Review of materials used in laser-aided additive manufacturing processes to produce metallic products. Front Mech Eng 14:282-298

7. Jiang J, Ma Y (2020) Path planning strategies to optimize accuracy, quality, build time and material use in additive manufacturing: a review. Micromachines 11(633):1-20

8. Jiang J, Xu X, Stringer J (2018) Support structures for additive manufacturing: a review. J Manuf Mater Process 2(64):1-23

9. Wong KV, Hernandez A (2012) A review of additive manufacturing. Int Sch Res Netw 2012:1-10

10. Zhang B, Li Y, Bai Q (2017) Defect formation mechanisms in selective laser melting: a review. Chin J Mech Eng 30:515-527

11. Sampath K (2009) Transverse-weld tensile properties of a new Al4Cu-2Si alloy as filler metal. J Mater Eng Perform 18:1218-1225

12. Mathers G (2002) The welding of aluminium and its alloys. Woodhead publishing limited, Cambridge

13. Galy C, Guen EL, Lacoste E, Arvieu C (2018) Main defects observed in aluminum alloy parts produced by SLM: from causes to consequences. Addit Manuf 22:165-175

14. Gu DD, Meiners W, Wissenbach K, Poprawe R (2012) Laser additive manufacturing of metallic components: materials, processes and mechanisms. Int Mater Rev 57(3):133-164

15. Sercombe TB, Li X (2016) Selective laser melting of aluminium and aluminium metal matrix composites: review. Mater Technol 31(2):77-85

16. Dadbakhsh S, Mertens R, Hao L, Humbeeck JV, Kruth JP (2019) Selective laser melting to manufacture 'in situ' metal matrix composites: a review. Adv Eng Mater 21(1801244):1-18

17. Zhang H, Zhu H, Qi T, Hu Z, Zeng X (2016) Selective laser melting of high strength $\mathrm{Al}-\mathrm{Cu}-\mathrm{Mg}$ alloys: processing, microstructure and mechanical properties. Mater Sci Eng A 656:47-54

18. Karg M, Ahuja B, Kuryntsev S, Gorunov A, Schmidth M Processability of high strength aluminium-copper alloys AW2022 and 2024 by laser beam melting in powder bed. In: Austin TX, 2014. 25th Solid Freedom Fabrication (SFF) Symposium, pp 420-436

19. Ahuja B, Karg M, Nagulin K, Schmidt M (2014) Fabrication and characterization of high strength $\mathrm{Al}-\mathrm{Cu}$ alloys processed using laser beam melting in metal powder bed. Phys Procedia 56:135-146

20. Han Q, Gu H, Setchi R (2019) Discrete element simulation of powder layer thickness in laser additive manufacturing. Powder Technol 352:91-102

21. Malekipour E, El-Mounayri H (2018) Common defects and contributing parameters in powder bed fusion AM process and their classification for online monitoring and control: a review. Int J Adv Manuf Technol 95:527-550

22. Anwar AB, Pham QC (2017) Selective laser melting of AlSi10Mg: effects of scan direction, part placement and inert gas flow velocity on tensile strength. J Mater Process Technol 240:388-396

23. Kimura T, Nakamoto $\mathrm{T}$ (2016) Microstructures and mechanical properties of A356 (A1Si7Mg0.3) aluminum alloy fabricated by selective laser melting. Mater Des 89:1294-1301 
24. Rakesh S, Raja A, Nadig P, Jayaganthan R, Vasa NJ (2019) Influence of working environment and built orientation on the tensile properties of selective laser melted AlSi10Mg alloy. Mater Sci Eng A 750:141-151

25. Read N, Wang W, Essa K, Attallah MM (2015) Selective laser melting of AlSi10Mg alloy: process optimisation and mechanical properties development. Mater Des 65:417-424

26. Hu Z, Zhang H, Zhu H, Xiao Z, Nie X, Zeng X (2019) Microstructure, mechanical properties and strengthening mechanisms of AlCu5MnCdVA aluminum alloy fabricated by selective laser melting. Mater Sci Eng A 759:154-166

27. Zhang J, Song B, Wei Q, Bourell D, Shi Y (2019) A review of selective laser melting of aluminum alloys: processing, microstructure, property and developing trends. J Mater Sci Technol 35(2): 270-284

28. Maamoun AH, Xue YF, Elbestawi MA, Veldhuis SC (2019) The effect of selective laser melting process parameters on the microstructure and mechanical properties of A16061 and AlSi10Mg alloys. Materials 12(12):1-24

29. Gu J, Bai J, Ding J, Williams S, Wang L, Liu K (2018) Design and cracking susceptibility of additively manufactured $\mathrm{Al}-\mathrm{Cu}-\mathrm{Mg}$ alloys with tandem wires and pulsed arc. J Mater Process Tech 262: 210-220

30. Olakanmi EO (2013) Selective laser sintering/melting (SLS/SLM) of pure $\mathrm{Al}, \mathrm{Al}-\mathrm{Mg}$, and $\mathrm{Al}-\mathrm{Si}$ powders: effect of processing conditions and powder properties. J Mater Process Technol 213:13871405

31. Wang L, Jiang X, Zhu Y, Zhu X, Sun J, Yan B (2018) An approach to predict the residual stress and distortion during the selective laser melting of AlSi10Mg parts. Int J Adv Manuf Technol 97:35353546

32. Mahamood RM, Akinlabi ET, Shukla M, Pityana S (2013) Characterizing the effect of laser power density on microstructure, microhardness, and surface finish of laser deposited titanium alloy. J Manuf Sci Eng 135(6): 1-4

33. Han Q, Jiao Y (2019) Effect of heat treatment and laser surface remelting on AlSi10Mg alloy fabricated by selective laser melting. Int J Adv Manuf Technol 102:3315-3324

34. Han Q, Setchi R, Lacan F, Gu D, Evans SL (2017) Selective laser melting of advanced Al-A12O3 nanocomposites: simulation, microstructure and mechanical properties. Mater Sci Eng A 698:162-173
35. Yuan $\mathrm{P}, \mathrm{Gu} \mathrm{D}$ (2015) Molten pool behaviour and its physical mechanism during selective laser melting of TiC/AlSi10Mg nanocomposites: simulation and experiments. J Phys D Appl Phys 48(3):116

36. Wang P, Gammer C, Brenne F, Prashanth K, Mendes R, Rümmeli M, Gemming T, Eckert J, Scudino S (2018) Microstructure and mechanical properties of a heat- treatable Al-3.5Cu-1.5Mg-1 Si alloy produced by selective laser melting. Mater Sci Eng A 711:562570

37. Kalpakjian S, Schmid SR Manufacturing engineering and technology. In, Singapore, 2014.

38. Larimian T, Kannan M, Grzesiak D, AlMangour B, Borkar T (2020) Effect of energy density and scanning strategy on densification, microstructure and mechanical properties of 316L stainless steel processed via selective laser melting. Mater Sci Eng A 770: $1-13$

39. Lei Z, Bi J, Chen Y, Chen X, Qin X, Tian Z (2019) Effect of energy density on formability, microstructure and micro-hardness of selective laser melted Sc- and Zr- modified 7075 aluminum alloy. Powder Technol 356:594-606

40. Pei W, Zhengying W, Zhen C, Jun D, Yuyang H, Junfeng L, Yatong Z (2017) The AlSi10Mg samples produced by selective laser melting: single track, densification, microstructure and mechanical behavior. Appl Surf Sci 408:38-50

41. Yusuf SM, Chen Y, Boardman R, Yang S, Gao N (2017) Investigation on porosity and microhardness of $316 \mathrm{~L}$ stainless steel fabricated by selective laser melting. Metals 7(2):1-12

42. Mukhopadhyay NK, Weatherly GC, Embury JD (2001) An analysis of microhardness of single-quasicrystals in the $\mathrm{Al}-\mathrm{Cu}-\mathrm{Co}-\mathrm{Si}$ system. Mater Sci Eng A 315:202-210

43. Koutny D, Palousek D, Pantelejev L, Hoeller C, Pichler R, Tesicky L, Kaiser J (2018) Influence of scanning strategies on processing of aluminum alloy EN AW 2618 using selective laser melting. Materials 11(2):1-18

44. Louvis E, Fox P, Sutcliffe CJ (2011) Selective laser melting of aluminium components. J Mater Process Technol 211:275-284

Publisher's note Springer Nature remains neutral with regard to jurisdictional claims in published maps and institutional affiliations. 